\title{
A Two-Stage Stochastic Mixed-Integer Programming Approach to the Competition of Biofuel and Food
} Production

\author{
Abstract
}

The multi-attribute biomass and food production (BFP) problem facing farmers and co-operatives is further complicated by uncertainties in crop yield and prices. In this paper, we present a two-stage stochastic mixed-integer programming (MIP) model that maximizes the economic and environmental benefits of food and biofuel production. The uncertain parameters of yield amount and price level are calculated using real data. Economic aspects include revenue obtained from biomass and food crop sales as well as costs related to seeding, production, harvesting, and transportation operations at the farm level. Environmental effects include greenhouse gas (GHG) emissions, carbon sequestration, soil erosion, and nitrogen leakage to water. The first-stage variables define binary decisions for allocating various land types to food and energy crops, while the second-stage variables are operational decisions related to harvesting, budget allocation, and amounts of different yield types. We present a decomposition algorithm, which is enhanced with specialized Benders cuts for solving this stochastic MIP problem. The computational efficiency of the proposed model and approach is demonstrated by applying it to a real case study involving switchgrass and corn production in the state of Kansas. We measure the solution quality and speed of the decomposition method over stochastic and deterministic models. Results indicate the significant benefit of using the stochastic yield-level information in an optimization model. The proposed stochastic MIP model provides important strategies and insights into decision making for biofuel and food production under uncertainty.

Keywords: Operations research (OR) in agriculture, OR in energy, stochastic programming, uncertainty, decomposition algorithm, Benders cutting planes, optimization, analytics, biofuel and food production, food security, sustainability

\section{Introduction}

Biofuel is a promising renewable energy source that can substitute for scarce fossil fuel and is currently utilized in many countries. Biofuel has mainly been produced from food (first-generation) crops; however, dependency on first-generation crops also increases concerns regarding the security of the food supply. Therefore, according to the Renewable Fuel Standards, the annual biofuel production from grain can be 15 billion gallons, while at least 16 billion gallons of ethanol should come from energy 
31 (second-generation) crops by 2022 (Schnepf \& Yacobucci, 2010). Food and energy crops have various

32 environmental and economic impacts. The trade-offs between economic and environmental benefits turn the decision making into a complex problem. In addition, it is important to incorporate uncertainties in yield amount with associated price level of energy and food crops in order to obtain better results relative to economic and environmental aspects. Thus, stakeholders in the agriculture business need a decision analysis tool that can handle uncertainties and also incorporate economic and environmental impacts of food and biomass production.

Existing deterministic mathematical models use point estimates and mean values in decision making. Although sensitivity analysis is utilized to cover the range of possible values of a parameter, it lacks the ability to provide decision strategies that will be successful in the long run. One of the most critical aspects in biomass production is the variability in yield amount since this is highly dependent on uncontrollable natural events, particularly changing weather conditions such as drought and high precipitation. The supply amount of a crop also affects its price in the market. Uncertainty in yield and associated price level should be incorporated into a decision-making tool since these factors directly impact the cost of production, profitability, and land utilization.

Stochastic programming can be used to deal with uncertain values of probabilistic parameters (Shapiro et al., 2009; Birge \& Louveaux, 1997; Wu \& Sen, 2000). Therefore, a more complete assessment of biomass and food production can be achieved with a stochastic model. In this paper, we propose a stochastic mixed-integer programming (MIP) model that incorporates various economic and environmental effects of biomass and food production (BFP) and provides the best decision strategies at the farm level for decision makers. One of the objectives of this study is to explicitly model the yield uncertainty involved in BFP by considering various scenarios. Due to this problem's high complexity, we also analyze the effect of different modeling techniques, such as deterministic and stochastic MIP.

54 Furthermore, we present a decomposition algorithm in order to solve the stochastic MIP more efficiently and increase its solution quality.

Previous research has studied the economic and environmental impacts of biofuel supply chains. For example, Ravindranath et al. (2011) assess the implications of projected large-scale biofuel production on land available for food production, water, biodiversity, rural development, and greenhouse gas (GHG) emissions in India. On the other hand, Chang et al. (2017) provide a review on life cycle analysis of energy consumption and GHG emissions for various biofuel vehicles using corn ethanol,

61 switchgrass ethanol, soybean biodiesel, and bio-hydrogen from corn ethanol. Tasca et al. (2017) perform 62 a life cycle assessment (LCA) comparison between two alternative forms of agricultural production and 
distribution of endive in northern Italy. On the other hand, García et al. (2016) develop a sustainability index using six indicators applied in all life cycle stages of two crops in Mexico considering the following: GHG emissions, land use, water use, energy balance, ethanol production costs, and number of employments generated.

In the literature, the majority of researchers focus on supply chain optimization; however, to our knowledge, none of these studies deals with food and biofuel production simultaneously in a stochastic programming model. Gebreslassie et al. (2012) define the optimal network design for a hydrocarbon biofuel supply chain by considering feedstock seasonality, demand variations, and government incentives. They apply a multi-cut L-shaped decomposition algorithm to solve the stochastic mixedinteger programming (MIP) model. Chen and Fan (2012) propose a two-stage stochastic MIP model via the Lagrangian relaxation method for designing a bioethanol supply chain network. Wiedenmann and Geldermann (2015) develop a two-stage stochastic programming model to analyze the supply chain of agricultural raw materials under price and supply uncertainty. Here, first-stage decisions involve the selection of suppliers for contract, while second-stage decisions define the value of penalty cost associated with unmet demand and quantity purchased from the no-contract supplier. In another study, Marufuzzaman et al. (2014) present a two-stage stochastic location-transportation MIP model to optimize costs and emissions of the biodiesel supply chain while capturing the impact of biomass supply and technology uncertainty. Mogale et al. $(2016,2017)$ investigate the food grain supply chain, transportation allocation problem of the Indian Public Distribution System (PDS), by developing a mixedinteger nonlinear programming (MINLP) model to minimize the transportation, inventory, and operational cost of shipping food grains from the procurement centers of producing states to the consuming state warehouses.

Very few optimization studies consider biomass and food production at the farm level, and many of them fall short on the stochastic nature of the problem. The model developed by Lin et al. (2014) involves a problem ranging in scope from biomass harvesting to ethanol distribution by using Miscanthus. Similarly, Sharma et al. (2013) formulate an MIP model for minimizing the transportation cost of switchgrass biomass to a biorefinery. They handle uncertainty in yield level by conducting sensitivity analysis. Venema and Calamai (2003) present a two-stage bioenergy plant location-allocation problem to address spatial distribution of the various land uses, and they plan rural energy considering both domestic and commercial energy demands. In another paper, Zhang et al. (2015) formulate the interactions among farmers, biofuel producers, blenders, and consumers in a bottom-up market equilibrium model to evaluate their profits and determine the optimal location and size of biorefinery 
facilities. In another biofuel supply chain problem (Tong et al., 2014), an MIP model is proposed for an optimal network design, while uncertainty of biomass availability and product demand are modeled with fuzzy numbers. However, the aforementioned models do not consider potential environmental effects of the supply chain in decision making.

The environmental effects of biomass and food production have been incorporated into a mathematical model in a limited number of studies. Cobuloglu and Büyüktahtakın (2014) propose an MIP model for the optimal land allocation of switchgrass while accounting for soil erosion, carbon sequestration, and carbon emissions of biomass production. Uncertainty in yield amounts, budget levels, and cropland availability are dealt with using a sensitivity analysis. Most of the other studies only consider carbon emissions. Affuso and Hite (2013) utilize a stochastic model by considering yield uncertainty and carbon emissions while allocating the land to first-generation biofuel crops. Similarly, Liu et al. (2014) consider carbon emissions for optimal design and planning of a biofuel supply chain in a deterministic MIP model. Giarola et al. (2012) propose a stochastic MIP model for an ethanol supply chain in order to decide the best biomass types and technology under uncertain biomass availability and the carbon trade value in the market. In order to find economically viable and environment-friendly production strategies, Kantas et al. (2015) incorporate carbon emissions and water pollution into a capacitated lot-sizing ethanol production model. In another study, Cobuloglu and Büyüktahtakın (2015a) propose a new stochastic analytical hierarchy process (AHP) that determines the most sustainable biomass crop considering economic, environmental, and social impacts of biomass and biofuel production. Gonela et al. (2015) present a stochastic optimization model for a first- and secondgeneration biofuel supply chain considering uncertainty in demand, bioethanol, and biomass price. Our approach is different from their method because we focus on land-use allocation decisions for the food and second-generation biofuel crops, and explicitly formulate the competition between food and biomass production with the corresponding economic and environmental impacts in a two-stage stochastic programming approach.

Our work differs from other studies in several aspects. In a previous study by Cobuloglu and

122 biomass production is analyzed in a deterministic model. The authors incorporate yield amount and 123 associated price level into the model with a piecewise linear function. Unlike Cobuloglu and 124 Büyüktahtakın (2015b), we develop a stochastic programming model to analyze the economic and 125 environmental impacts of BFP and incorporate uncertainty in two important parameters, yield and price 126 level, into the stochastic MIP model. We also propose a decomposition-based algorithm enhanced with 
Benders cutting planes to address the high computational complexity of the BFP problem in a stochastic 128 programming setting.

129

Contributions of this work can be summarized as follows:

- Most stochastic models in the biofuel field are developed primarily for designing the biofuel supply chain. To the best of our knowledge, this is the first stochastic programming study that models the competition of food and biomass production at the farm level. To the best of our knowledge, this is also the first stochastic programming study that incorporates both economic and environmental impacts simultaneously, while considering yield uncertainty. In addition to costs of seeding, production, harvesting, and transportation, a compact set of environmental impacts, namely soil erosion prevention, carbon emissions and sequestration, and nitrogen pollution, are integrated into the model.

- In this study, we utilize real data to obtain the probability of random events-yield amounts and price levels of crops. Thus, we first define the probability distribution of yield amounts. For the scenario generation, the probability density function is discretized into three values with associated probabilities. Then we find the corresponding price levels of each yield value by utilizing a linear regression function. The data and the function relating yield and price can also be used for other agricultural applications as well as for the cost-benefit analysis of corn and switchgrass production under yield and price uncertainty.

- Due to the computational complexity of the stochastic MIP model, we perform a decomposition algorithm enhanced with Benders cuts, which are specified for strengthening the MIP formulation of the BFP problem. Computational efficiencies such as solution quality and time of the deterministic, stochastic, and decomposition models are presented in the analysis section. We also provide the benefit of solving the stochastic programming model over its deterministic counterpart to demonstrate the importance of incorporating uncertainty into the optimization model. The results also demonstrate that Benders decomposition and cuts work well for this problem, implying that this approach can provide useful computational benefit for other similar problems.

- This model has been developed for energy and food crops in general; however, its use is demonstrated on an application to switchgrass and corn production. The generalizability of the problem to other energy and food crops is an important contribution because this modeling framework can be adapted to different crops, such as wheat and Miscanthus, with small 
changes in the model and update in the data. Efficiency of the proposed decomposition algorithm can also be tested in similar type problems in the future.

The remainder of this paper is organized as follows: The problem statement and notations are presented in Section 2. The stochastic MIP model as well as its decomposition are provided in detail in Section 3. Input data for deterministic and uncertain parameters along with scenario generation are described in Section 4. A case study with all computational results, comparisons, and sensitivity analysis is provided in Section 5. Finally, conclusions and future directions are discussed in Section 6.

\section{Problem Definition}

Our goal in this paper is to provide a decision-making model that maximizes the total economic and environmental benefits of biofuel and food production under uncertainty in the long run. We utilize switchgrass for biofuel production since it has been one of the most favorable energy crops with various environmental benefits, low input requirements, and high energy yield. It is also a perennial grass that is native to North America. Among different alternatives for food crops, corn is considered a source of both food and biofuel production in our study due to its prevalent cultivation in the U.S.

Switchgrass and corn have different economic and environmental benefits. Switchgrass is a lowinput crop and has a minimum ten-year life expectancy. On the other hand, corn requires a high amount of fertilizer and needs seeding each year. Environmental benefits of switchgrass include reduction in greenhouse gas emissions, storage of soil organic carbon (SOC), and prevention of soil erosion due to its long root system (Liebig et al., 2008). The environmental impacts of different crops change temporally and spatially. On the other hand, when compared with switchgrass, corn has fewer ecological benefits while potentially damaging the environment. The yield of switchgrass and corn are both affected by weather conditions. In addition, the price level of corn grain in the food market is negatively correlated with its supply amount. Therefore, a compact decision-making system is needed, not only to incorporate these economic and environmental trade-offs but also to handle the uncertainty of yield amounts and price levels.

Yield amounts of switchgrass and corn are affected by uncertain weather conditions. Yield amount is included in the model by considering three possible states of yield: high, medium, and low. The price of corn grain that goes to the food market is affected each year by the amount of corn yield. On the other hand, the price of switchgrass, corn stover, and corn grain that go to a biorefinery is considered deterministic due to long-term contracts between farmers and the biorefinery. Fig. 1 displays a scenario tree representing yield and price scenarios together with associated probabilities $\left(\varepsilon_{s}\right)$ for each scenario $s$ in each time period of a ten-year horizon. In the first year, low-, medium-, and high- 
yield scenarios have probabilities $\varepsilon_{1}, \varepsilon_{2}$, and $\varepsilon_{3}$, respectively. In order to obtain the probability of each

191 scenario in the second year, the probabilities of each yield (high, medium, and low) state are multiplied

192 with the probability of a previous state (parent node). Having three states from each node results in

19359,049 scenarios for a ten-year planning horizon. An example of the calculation of yield amount and

194 price levels as well as associated probabilities for each scenario is presented in Figure 1.

195

196

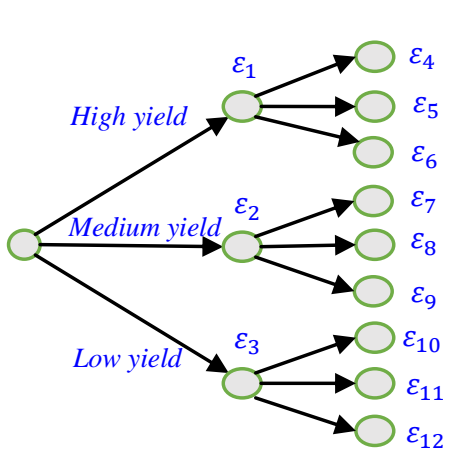

$t=0$

$t=1$

$t=2$

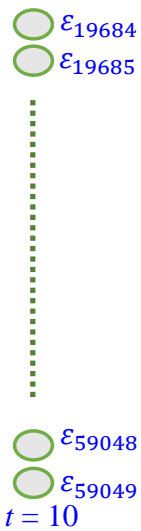

Fig. 1. Scenario tree for uncertain yield amount and associated probabilities (note that uncertain price level is determined as a function of yield amount in each state and time period).

All sequential processes in BFP and outputs of the proposed stochastic programming model are displayed in Fig. 2. Sequential processes considered in the model begin with the allocation of energy and food crops to different land types. Then, the cultivation of energy and food crops on different land types leads to various yield levels. Once each crop is grown, the harvesting of yield types is realized on the selected zones. Finally, harvested yield types are transported to different markets.

Model outputs demonstrate decisions for various processes. First, each zone of the different land types is allocated to a crop type. Based on the match between crop and land type, a seeding budget is defined. A production budget consisting of fertilization and rental cost is determined for producing switchgrass and corn in the allocated zones. Then, crop types to harvest, harvested zones, time period of harvesting, and amount of harvesting are defined. A portion of the overall budget is also allocated for harvesting operations. Finally, the quantity of harvesting also determines the budget required for transporting the harvested yield. Note that the model oversees all processes and provides optimal decision strategies for each step simultaneously. 


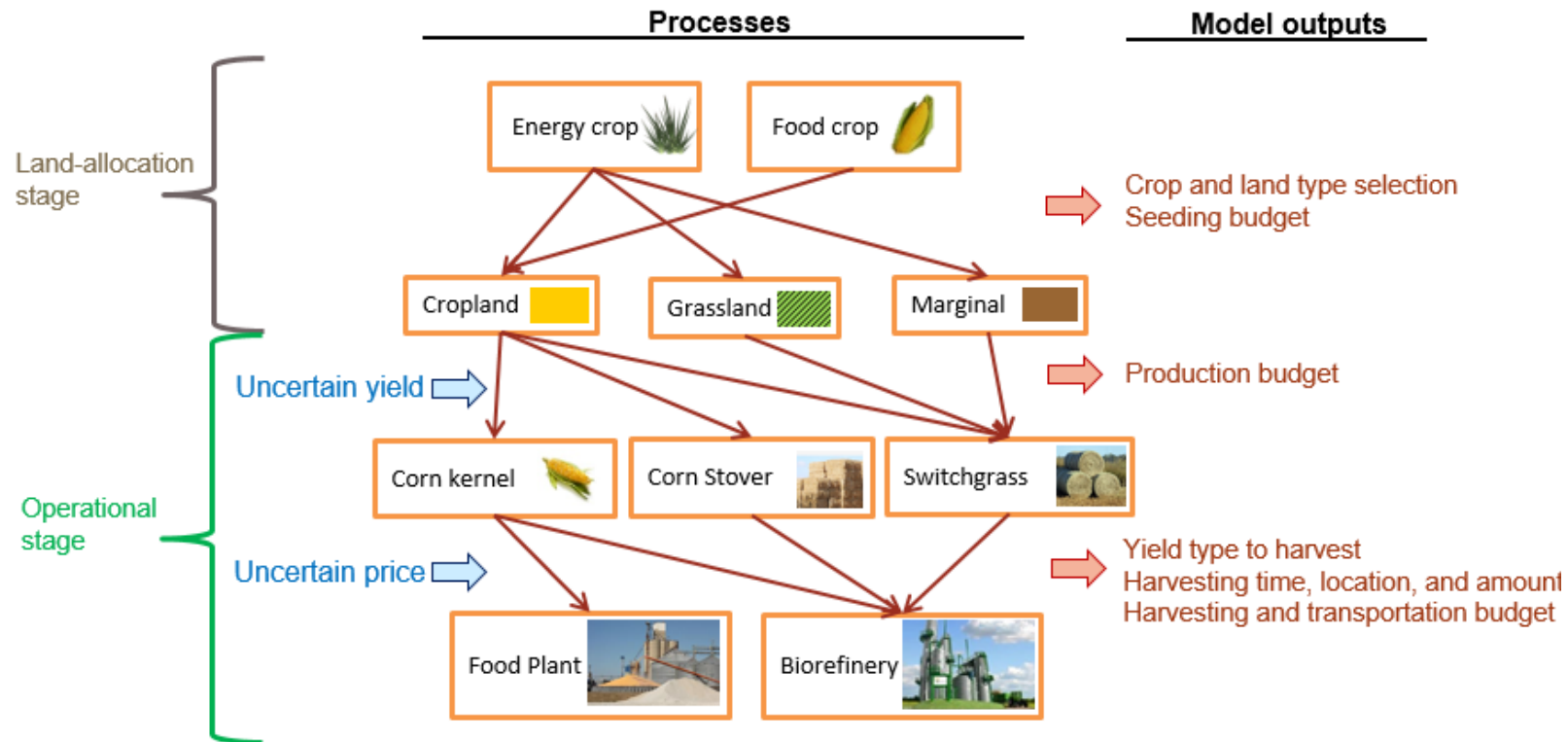

Fig. 2. Model inputs and outputs as well as processes in food and biofuel production.

The establishment of switchgrass is considered a strategic decision since once allocated, it has

214 ten years of life without reseeding. The land allocated for corn is assumed to not change during the

215 planning horizon. We also assume that utilized lands can be partially harvested. Considering this setting,

216 we propose a two-stage stochastic optimization model. In the first (land allocation) stage, land allocation

217 to different crop types is decided, and in the second (operational) stage, the amount of biomass and

218 food yield, harvesting decisions, and quantity of harvesting are decided. These decisions also define the

219 budget allocation for each farm operation.

220 Nomenclature

221 Sets

$222 \quad I \quad$ Set of rows of cultivation area

$223 J \quad$ Set of columns of cultivation area

$224 \quad K \quad$ Set of crop types

$225 \quad V \quad$ Set of yield types

$226 T$ Set of time periods in modeling horizon

$227 \quad S \quad$ Set of scenarios

$228 \quad C R \quad$ Set of cropland zones in cultivation area

$229 G R \quad$ Set of grassland zones in cultivation area

$230 \quad M R \quad$ Set of marginal land zones in cultivation area

231 Indices 


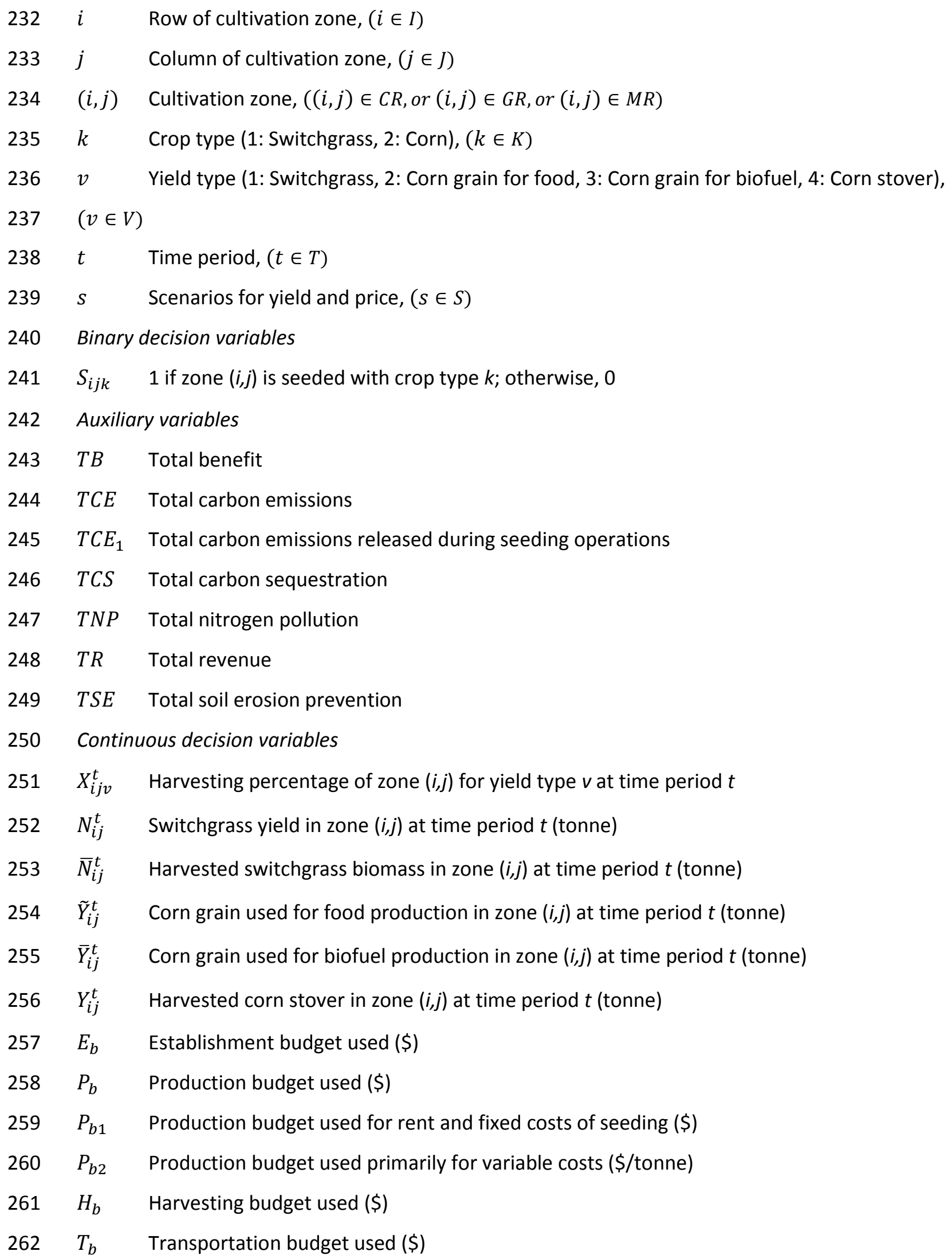


$263 \quad Z \quad$ Decision variable representing subproblem and associated with optimality cuts

$264 \Pi_{i j t s}^{1} \quad$ Dual variable associated with constraint (c9)

$265 \Pi_{i j t s}^{2} \quad$ Dual variable associated with constraint (c10)

$266 \Pi_{i j t s}^{3} \quad$ Dual variable associated with constraint (c11)

$267 \Upsilon_{i j t}^{1} \quad$ Dual variable associated with constraint (c12)

$268 Y_{i j t}^{2} \quad$ Dual variable associated with constraint (c13)

$269 \Upsilon_{i j t}^{3} \quad$ Dual variable associated with constraint (c14)

$270 \quad L_{i j t s}^{1} \quad$ Dual variable associated with constraint (c15)

$271 \quad \zeta_{i j t s}^{2} \quad$ Dual variable associated with constraint (c16)

$272 \quad \mathrm{~L}_{i j t s}^{3} \quad$ Dual variable associated with constraint (c17)

$273 \quad \zeta_{i j t s}^{4} \quad$ Dual variable associated with constraint (c18)

$274 \quad 4_{i j t s}^{5} \quad$ Dual variable associated with constraint (c19)

$275 x_{t s} \quad$ Dual variable associated with constraint (c20)

$276 \quad \chi_{s} \quad$ Dual variable associated with constraint (c21)

$277 \pi_{i j v s}^{t}$ Dual variable associated with constraint (c22)

278 Parameters

$279 \alpha \quad$ Weight of profit

$280 \quad \beta \quad$ Weight of environmental effects

$281 p_{v}^{t} \quad$ Sale price of yield type $v$ at time period $t$ (\$/tonne)

$282 \quad \varepsilon_{S} \quad$ Probability associated with scenario $s$

$283 A_{i j v} \quad$ Potential yield of yield type $v$ in zone $(i, j)$ (tonne)

$284 S E_{i j k} \quad$ Economic value of soil erosion prevention in zone $(i, j)$ via crop type $k(\$)$

$285 \phi \quad$ Soil erosion prevention reduction constant for harvested yield

$286 C S_{i j k} \quad$ Economic value of carbon sequestration in zone $(i, j)$ via crop type $k(\$)$

$287 \xi \quad$ Carbon sequestration reduction constant for harvested yield

$288 \sigma_{k} \quad$ Carbon emissions penalty of seeding crop type $k(\$)$

$289 \rho_{v} \quad$ Carbon emissions penalty of harvesting yield type $v(\$)$

$290 \omega_{v} \quad$ Carbon emissions penalty of production operations for yield type $v$ (\$/tonne)

$291 \tau \quad$ Carbon emissions penalty of transporting yield (\$/tonne-km)

$292 \eta \quad$ Economic damage caused by nitrogen pollution $(\$ / \mathrm{kg})$

$293 \quad f_{k} \quad$ Nitrogen fertilizer applied for crop type $k(\mathrm{~kg})$ 

$294 \quad \mu_{k} \quad$ Percent nitrogen uptake by crop type $k$
$295 \quad \psi \quad$ Percent nitrogen contamination (leaching) in drinking water
$296 \pi_{t} \quad$ Growth factor of switchgrass after $t$ years of establishment
$297 \quad e_{v} \quad$ Biofuel conversion factor for yield type $v$ (liter/tonne)
$298 \Delta \quad$ Fraction of facility capacity assigned to biofuel production from switchgrass and corn biomass
$299 \quad C_{t} \quad$ Biofuel production capacity of facility at time period $t$ (liter)
$300 \quad B \quad$ Total available budget in planning horizon (\$)
$301 T E C_{i j k}$ Total expected establishment cost for crop type $k$ in zone $(i, j)(\$)$
$302 \epsilon_{k} \quad$ Fixed cost of producing crop type $k$ per cultivation zone (\$)
$303 R C_{i j} \quad$ Rental cost of cultivation zone $(i, j)(\$)$
$304 \gamma_{v} \quad$ Variable cost of producing yield type $v$ (\$/tonne)
$305 \quad \delta_{v} \quad$ Fixed cost of harvesting yield type $v$ per zone (\$)
$306 \theta_{v} \quad$ Variable cost of harvesting yield type $v(\$ /$ tonne)
$307 D_{i j} \quad$ Distance of zone $(i, j)$ to facility $(\mathrm{km})$
$308 \quad F_{v} \quad$ Fixed cost of transporting yield type $v(\$)$
$309 V_{v} \quad$ Variable cost of transporting yield type $v(\$ /$ tonne $\mathrm{km})$
$310 \lambda \quad$ Food-security defining percentage of cropland allowed for only food crop production

\section{3. Mathematical Solution Approaches}

312 In this section, we explain the two-stage stochastic MIP model proposed for food and biomass 313 production, decomposition algorithm with Benders cuts, along with the master problem (MP) (land 314 allocation), primal subproblem (SP) (operational), and dual SP.

\section{$315 \quad 3.1$ Stochastic Model}

Uncertainties involved in the decision-making process require the development of a stochastic

317 model. Scenarios related to yield amount and price level along with their corresponding probabilities are

318 integrated into the optimization model. The stochastic MIP model formulation is then given as

$$
\text { Maximize } T B=\alpha\left(T R-\left(E_{b}+P_{b}+H_{b}+T_{b}\right)\right)+\beta(T S E+T C S-T C E-T N P)
$$

319 Subject to:

320 Auxiliary variables

$$
\begin{aligned}
T R & =\sum_{i} \sum_{j} \sum_{t} \sum_{s} \varepsilon_{s}\left(p_{1 s}^{t} \bar{N}_{i j s}^{t}+p_{2 S}^{t} \tilde{Y}_{i j s}^{t}+p_{3 S}^{t} \bar{Y}_{i j s}^{t}+p_{4 S}^{t} Y_{i j s}^{t}\right) \\
E_{b} & =\sum_{i} \sum_{j} \sum_{k} T E C_{i j k} S_{i j k}
\end{aligned}
$$




$$
\begin{aligned}
& P_{b}= \sum_{i} \sum_{j}\left(\sum_{k}\left(\epsilon_{k}+R C_{i j}\right) S_{i j k}+\sum_{t} \sum_{s} \varepsilon_{s}\left(\gamma_{1} \bar{N}_{i j s}^{t}+\gamma_{2} \tilde{Y}_{i j s}^{t}+\gamma_{3} \bar{Y}_{i j s}^{t}+\gamma_{4} Y_{i j s}^{t}\right)\right) \\
& H_{b}= \sum_{i} \sum_{j} \sum_{t} \sum_{s} \varepsilon_{s}\left(\sum_{v} \delta_{v} X_{i j v s}^{t}+\theta_{1} \bar{N}_{i j s}^{t}+\theta_{2} \tilde{Y}_{i j s}^{t}+\theta_{3} \bar{Y}_{i j s}^{t}+\theta_{4} Y_{i j s}^{t}\right) \\
& T_{b}= \sum_{i} \sum_{j} \sum_{t} \sum_{s} \varepsilon_{s}\left(\sum_{v} F_{v} X_{i j v s}^{t}+D_{i j}\left(V_{1} \bar{N}_{i j s}^{t}+V_{2} \tilde{Y}_{i j s}^{t}+V_{3} \bar{Y}_{i j s}^{t}+V_{4} Y_{i j s}^{t}\right)\right) \\
& T S E= \sum_{i} \sum_{j} \sum_{t} \sum_{s} \varepsilon_{s}\left(S E_{i j 1}\left(\frac{N_{i j s}^{t}-\phi \bar{N}_{i j s}^{t}}{A_{i j 1 s}}\right)+S E_{i j 2}\left(\frac{\tilde{Y}_{i j s}^{t}+\bar{Y}_{i j s}^{t}}{A_{i j 2 s}}-\phi \frac{Y_{i j s}^{t}}{A_{i j 4 s}}\right)\right) \\
& T C E= \sum_{i} \sum_{j}\left(\sum_{k} \sigma_{k} S_{i j k}\right. \\
&+\sum_{t} \sum_{s} \varepsilon_{s}\left(\sum_{v} \rho_{v} X_{i j v s}^{t}+\omega_{1} \bar{N}_{i j s}^{t}+\omega_{2} \tilde{Y}_{i j s}^{t}+\omega_{3} \bar{Y}_{i j s}^{t}+\omega_{4} Y_{i j s}^{t}\right. \\
&\left.\left.+D_{i j} \tau\left(\bar{N}_{i j s}^{t}+\tilde{Y}_{i j s}^{t}+\bar{Y}_{i j s}^{t}+Y_{i j s}^{t}\right)\right)\right) \\
& T N P=\eta \sum_{i} \sum_{j} \sum_{k} S_{i j k} f_{k}\left(1-\mu_{k}\right) \psi
\end{aligned}
$$

\section{Seeding constraints}

$$
\begin{aligned}
& \sum_{k} S_{i j k} \leq 1 \quad \forall i, j \\
& S_{i j 2} \leq 0 \quad \forall(i, j) \in G R \text { or } M R \\
& \sum_{(i, j) \in C R} S_{i j 1} \leq(1-\lambda)|C R| \quad \forall t
\end{aligned}
$$

322 Yield constraints

$$
\begin{aligned}
& N_{i j s}^{t}=A_{i j 1 s} \pi_{t} S_{i j 1} \quad \forall i, j, t, s \\
& \tilde{Y}_{i j s}^{t}+\bar{Y}_{i j s}^{t}=A_{i j 2 s} S_{i j 2} \quad \forall i, j, t, s \\
& Y_{i j s}^{t} \leq A_{i j 4 s} S_{i j 2} \quad \forall i, j, t, s
\end{aligned}
$$

323 Harvesting constraints

$$
\begin{aligned}
& X_{i j 1 s}^{t} \leq S_{i j 1} \quad \forall i, j, t, s \\
& X_{i j 2 s}^{t}+X_{i j 3 s}^{t}=S_{i j 2} \quad \forall i, j, t, s \\
& X_{i j 4}^{t} \leq S_{i j 2} \quad \forall i, j, t, s
\end{aligned}
$$

Harvested yield constraints 
$\bar{N}_{i j s}^{t}-A_{i j 1 s} \pi_{t} X_{i j 1 s}^{t} \leq 0 \quad \forall i, j, t, s$

$\bar{N}_{i j s}^{t}-N_{i j s}^{t} \leq 0 \quad \forall i, j, t, s$

$\tilde{Y}_{i j s}^{t}-A_{i j 2 s} X_{i j 2 s}^{t} \leq 0 \quad \forall i, j, t, s$

$\bar{Y}_{i j s}^{t}-A_{i j 3 s} X_{i j 3 s}^{t} \leq 0 \quad \forall i, j, t, s$

$Y_{i j s}^{t}-A_{i j 4 s} X_{i j 4 s}^{t} \leq 0 \quad \forall i, j, t, s$

Biofuel capacity constraint

$\sum_{i} \sum_{j}\left(e_{1} \bar{N}_{i j s}^{t}+e_{3} \bar{Y}_{i j s}^{t}+e_{4} Y_{i j s}^{t}\right) \leq \Delta C_{t} \quad \forall t, s$

326 Budget constraint

$E_{b}+P_{b}+H_{b}+T_{b} \leq B$

327 Constraints on variables

$N_{i j s}^{t}, \bar{N}_{i j s}^{t}, \tilde{Y}_{i j s}^{t}, \bar{Y}_{i j s}^{t}, Y_{i j s}^{t} \geq 0 \quad \forall i, j, t, s$

$S_{i j k} \in\{0,1\} \quad \forall i, j, k$

$0 \leq X_{i j 1 s}^{t} \leq 1 \quad \forall i, j, t, s$

The multi-objective formulation in the objective function maximizes total benefits (TB) using a weighted sum of economic and environmental benefits. For the economic benefits, $\alpha$ is multiplied with profit, which is defined by subtracting the budget allocated to farm operations, establishment $\left(\mathrm{E}_{\mathrm{b}}\right)$, production $\left(\mathrm{P}_{b}\right)$, harvesting $\left(\mathrm{H}_{b}\right)$, and transportation $\left(T_{b}\right)$ from the total revenue (TR). Net benefits of environmental impacts, namely total soil erosion (TSE), total carbon sequestration (TCS), total carbon emissions (TCE), and total nitrogen pollution (TNP), are multiplied with $\beta$ to determine their priority in decision making.

Economic impacts in the objective function are formulized in Eqs. a2-a6. Eq. a2 defines the revenue by multiplying the amount of each yield type with its corresponding selling price. Eq. a3 gives the establishment budget by multiplying seeding decisions with total establishment cost of seeding crop type $k$ at zone $(i, j)$. Eq. a4 formulizes the production budget by incorporating fixed costs (fertilization and rent) with variables costs (fertilization), depending on the amount of each crop type. Similarly, Eq. a5 defines the harvesting budget by including fixed and variables costs of harvesting for each yield type. For the calculation of transportation budget, Eq. a6 incorporates a fixed cost for transporting each yield type and a variable cost, which depends on yield type and distance between zone $(i, j)$ and demand point.

Economic values of environmental impacts in the objective function are formulized in Eqs. a7-

344 a10. Eq. a7 defines the economic value of soil erosion prevention by considering the effect of yield amount produced and harvested on different land types. Similarly, Eq. a8 determines the economic 
value of carbon sequestration by considering the production and harvesting of different yield types on different soil types. Eq. a9 provides the total carbon emissions that occur during farm operations such as seeding, production, harvesting, and transportation. Eq. a10 calculates the negative economic value of nitrogen pollution by considering the percentage of nitrogen leakage to ground water for each crop type.

The objective function is subject to seeding, yield, harvesting, capacity, and budget constraints. Eq. a11 ensures that only one crop can be established in each zone. Eq. a12 prevents the production of food crops on grassland and marginal land. For security of the food supply, Eq. a13 limits the allocation of energy crops to cropland with a percentage. Eqs. a14-a16 determine the yield amount given that the associated crop type is seeded in that zone for each scenario s. Eq. a14 defines the switchgrass yield by multiplying the growth factor and maximum yield that can be obtained in a zone if it is seeded. Eq. a15 states that total corn grain yield that goes to food or biofuel production equals the maximum corn yield production in the corresponding zone. Similarly, Eq. a16 ensures that corn stover yield cannot exceed the maximum yield grown in that zone in the case where corn is seeded. Eqs. a17-a19 determine the harvesting regulations and policies for each scenario s. Eq. a17 states that switchgrass can be harvested only if it is seeded. Eq. a18 ensures that corn grain is harvested for either food or biofuel production once it is seeded. Similar to switchgrass biomass, Eq. a19 ensures that it can be harvested only if corn is seeded in that zone. Eqs. a20 and a21 limit the amount of harvested switchgrass with multiplication of its harvesting decision, growth factor, and maximum yield, or with the switchgrass amount available in that field. Eqs. a22-a24 limit the amount of harvested corn grain for food, corn grain for biofuel, and corn stover, respectively, by multiplying their available grown yield amounts with harvesting decisions. Eq. a25 states that the summation of biomass types (switchgrass, corn grain, and corn stover) multiplied with their conversion factors cannot exceed the available biofuel conversion capacity of the biorefinery. Eq. a26 limits the budget allocation to different farm operations, seeding, production, harvesting, and transportation with the available budget. Eq. a27 imposes non-negativity on switchgrass, harvested switchgrass, corn grain for the food market, corn grain for biofuel production, and corn stover, respectively. Eq. a28 defines seeding decisions as binary variables. Finally, Eq. a29 sets the value for harvesting decisions between 0 and 1 .

\subsection{Decomposition Algorithm}

In order to solve the proposed stochastic MIP model, we follow a similar approach to the Benders decomposition for our specific problem (Benders, 1962; Sherali \& Fraticelli, 2002). In particular, we decompose the problem into an MP, comprising only the first-stage variables and related 
constraints, and an SP that involves second-stage decisions. The first-stage variables refer to decision

379 variables that must be decided at the beginning of a period before the realization of random events, namely yield amounts. Thus, seeding decisions that answer the land allocation problem are first-stage variables. Second-stage variables refer to decision variables to be decided at the end of a time period

382 after the uncertain event parameter is observed. In the second stage, after the yield uncertainty is

383 revealed, the operational problem, including decisions of the production amounts, harvesting, and

384 budget allocation, is solved.

\subsubsection{Master Problem (Land Allocation)}

387 deterministic part of the whole model and maximizes the master benefit (MB). The MP includes $Z$, which represent the benefits from the subproblem. The MP formulation is presented as follows:

$$
\text { Maximize } M B=\alpha\left(-\left(E_{b}+P_{b 1}\right)\right)+\beta\left(-T C E_{1}-T N P\right)+Z
$$

Auxiliary variables

$$
\begin{aligned}
& E_{b}=\sum_{i} \sum_{j} \sum_{k} T E C_{i j k} S_{i j k} \\
& P_{b 1}=\sum_{i} \sum_{j}\left(\sum_{k}\left(\epsilon_{k}+R C_{i j}\right) S_{i j k}\right) \\
& T C E_{1}=\sum_{i} \sum_{j} \sum_{k} \sigma_{k} S_{i j k} \\
& T N P=\eta \sum_{i} \sum_{j} \sum_{k} S_{i j k} f_{k}\left(1-\mu_{k}\right) \psi
\end{aligned}
$$

Seeding constraints

$\sum_{k} S_{i j k} \leq 1 \quad \forall i, j$

$S_{i j 2} \leq 0 \quad \forall(i, j) \in G R$ or $M R$

$\sum_{(i, j) \in C R} S_{i j 1} \leq(1-\lambda)|C R| \quad \forall t$

391 Constraints for optimality and feasibility

$W\left(S_{i j k}, \hat{G}_{i j k}^{l}\right) \geq 0 \quad \forall l \in \Omega^{\text {feas }}$

$Z \leq W\left(S_{i j k}, \bar{G}_{i j k}^{l}\right) \quad \forall l \in \Omega^{o p t}$

392 Constraints on decision variables

$S_{i j k} \in\{0,1\} \quad \forall i, j, k$

$Z \geq 0$ 
393 where $\widehat{G}_{i j k}^{l}$ and $\bar{G}_{i j k}^{l}$ represent extreme rays and optimal solution values of the dual SP, respectively; $W($.)

394 is a function used to define the $I^{\text {th }}$ feasibility or optimality cut; and $\Omega^{\text {feas }}$ and $\Omega^{\text {opt }}$ represent the set of

395 feasibility and optimality inequalities, respectively.

\subsubsection{Primal Subproblem (Operational subproblem)}

397

The primal subproblem includes constraints with linear and binary variables from the entire model. Note that the primal SP maximizes the primal benefit (PB), which is represented by $Z$ in the master problem. Given a solution from the MP, $\underline{S}_{i j k}$, the primal SP formulation is presented as follows:

Maximize $P B=\alpha\left(T R-\left(P_{b 2}+H_{b}+T_{b}\right)\right)+\beta\left(T S E+T C S-T C E_{2}\right)$

400

Auxiliary variables

$$
\begin{aligned}
T R & =\sum_{i} \sum_{j} \sum_{t} \sum_{s} \varepsilon_{s}\left(p_{1 s}^{t} \bar{N}_{i j s}^{t}+p_{2 s}^{t} \tilde{Y}_{i j s}^{t}+p_{3 s}^{t} \bar{Y}_{i j s}^{t}+p_{4 s}^{t} Y_{i j s}^{t}\right) \\
P_{b 2}= & \sum_{i} \sum_{j} \sum_{t} \sum_{s} \varepsilon_{s}\left(\gamma_{1} \bar{N}_{i j s}^{t}+\gamma_{2} \tilde{Y}_{i j s}^{t}+\gamma_{3} \bar{Y}_{i j s}^{t}+\gamma_{4} Y_{i j s}^{t}\right) \\
H_{b}= & \sum_{i} \sum_{j} \sum_{t} \sum_{s} \varepsilon_{s}\left(\sum_{v} \delta_{v} X_{i j v s}^{t}+\theta_{1} \bar{N}_{i j s}^{t}+\theta_{2} \tilde{Y}_{i j s}^{t}+\theta_{3} \bar{Y}_{i j s}^{t}+\theta_{4} Y_{i j s}^{t}\right) \\
T_{b}= & \sum_{i} \sum_{j} \sum_{t} \sum_{s} \varepsilon_{s}\left(\sum_{v} F_{v} X_{i j v s}^{t}+D_{i j}\left(V_{1} \bar{N}_{i j s}^{t}+V_{2} \tilde{Y}_{i j s}^{t}+V_{3} \bar{Y}_{i j s}^{t}+V_{4} Y_{i j s}^{t}\right)\right) \\
T S E= & \sum_{i} \sum_{j} \sum_{t} \sum_{s} \varepsilon_{s}\left(S E_{i j 1}\left(\frac{N_{i j s}^{t}-\phi \bar{N}_{i j s}^{t}}{A_{i j 1 s}}\right)+S E_{i j 2}\left(\frac{\tilde{Y}_{i j s}^{t}+\bar{Y}_{i j s}^{t}}{A_{i j 2 s}}-\phi \frac{Y_{i j s}^{t}}{A_{i j 4 s}}\right)\right) \\
T C S= & \sum_{i} \sum_{j} \sum_{t} \sum_{s} \varepsilon_{s}\left(C S_{i j 1}\left(\frac{N_{i j s}^{t}-\xi \bar{N}_{i j s}^{t}}{A_{i j 1}}\right)+C S_{i j 2}\left(\frac{\tilde{Y}_{i j s}^{t}+\bar{Y}_{i j s}^{t}}{A_{i j 2 s}}-\xi \frac{Y_{i j s}^{t}}{A_{i j 4 s}}\right)\right) \\
& \left.+D_{i j} \tau\left(\bar{N}_{i j s}^{t}+\tilde{Y}_{i j s}^{t}+\bar{Y}_{i j s}^{t}+Y_{i j s}^{t}\right)\right) \\
T C E_{2}= & \sum_{i} \sum_{j} \sum_{t} \sum_{s} \varepsilon_{s}\left(\sum_{v} \rho_{v} X_{i j v s}^{t}+\omega_{1} \bar{N}_{i j s}^{t}+\omega_{2} \tilde{Y}_{i j s}^{t}+\omega_{3} \bar{Y}_{i j s}^{t}+\omega_{4} Y_{i j s}^{t}\right.
\end{aligned}
$$

401 Subject to:

402 Yield constraints

$$
\begin{aligned}
& N_{i j s}^{t}=A_{i j 1 s} \pi_{t} \underline{S}_{i j 1} \quad \forall i, j, t, s \\
& \tilde{Y}_{i j s}^{t}+\bar{Y}_{i j s}^{t}=A_{i j 2 s} \underline{S}_{i j 2} \quad \forall i, j, t, s
\end{aligned}
$$


$Y_{i j s}^{t} \leq A_{i j 4 s} S_{-i j 2} \quad \forall i, j, t, s$

403 Harvesting constraints

$X_{i j 1 s}^{t} \leq \underline{S}_{i j 1} \quad \forall i, j, t, s$

$X_{i j 2 s}^{t}+X_{i j 3 s}^{t}=\underline{S}_{i j 2}^{1} \quad \forall i, j, t, s$

$X_{i j 4 s}^{t} \leq \underline{S}_{i j 2} \quad \forall i, j, t, s$

404 Harvested yield constraints

$\bar{N}_{i j s}^{t}-A_{i j 1 s} \pi_{t} X_{i j 1 s}^{t} \leq 0 \quad \forall i, j, t, s$

$\bar{N}_{i j s}^{t}-N_{i j s}^{t} \leq 0 \quad \forall i, j, t, s$

$\tilde{Y}_{i j s}^{t}-A_{i j 2 s} X_{i j 2 s}^{t} \leq 0 \quad \forall i, j, t, s$

$\bar{Y}_{i j s}^{t}-A_{i j 3 s} X_{i j 3 s}^{t} \leq 0 \quad \forall i, j, t, s$

$Y_{i j s}^{t}-A_{i j 4 s} X_{i j 4 s}^{t} \leq 0 \quad \forall i, j, t, s$

405 Biofuel capacity constraint

$\sum_{i} \sum_{j}\left(e_{1} \bar{N}_{i j s}^{t}+e_{3} \bar{Y}_{i j s}^{t}+e_{4} Y_{i j s}^{t}\right) \leq \Delta C_{t} \quad \forall t, s$

406 Budget constraint

$P_{b 2}+H_{b}+T_{b} \leq\left(B-P_{b 1}-E_{b}\right)$

407 Constraint on harvesting

$0 \leq X_{i j 1 s}^{t} \leq 1 \quad \forall i, j, t, s$

408 Constraints on variables

$N_{i j s}^{t}, \bar{N}_{i j s}^{t}, \tilde{Y}_{i j s}^{t}, \bar{Y}_{i j s}^{t}, Y_{i j s}^{t} \geq 0 \quad \forall i, j, t, s$

409

410

\section{$411 \quad$ 3.2.2 Dual Subproblem}

412 For the decomposition algorithm, we first define dual variables associated with the constraints

413 of the primal SP formulation. The dual subproblem involves minimization of the dual benefit (DB), which

414 is equal to the PB in the case of optimality. Given a solution from the MP, $\underline{S}_{i j k}$, and letting $G_{i j k}$ define the

415 set of dual variables, the dual SP is formulated as follows:

Minimize $W\left(\underline{S}_{i j k}, G_{i j k}\right)$

$$
\begin{aligned}
& =\sum_{i j t s}\left(\left(A_{i j 1 s} \pi_{t} \underline{S}_{i j 1}\right) \Pi_{i j t s}^{1}+\left(A_{i j 2 s} \underline{S}_{i j 2}\right) \Pi_{i j t s}^{2}+\left(A_{i j 4 s} S_{i j 2}\right) \Pi_{i j t s}^{3}+\underline{S}_{i j 2} \Upsilon_{i j t s}^{1}+\underline{S}_{i j 2} \Upsilon_{i j t s}^{2}\right. \\
& \left.+\underline{S}_{i j 2} \Upsilon_{i j t s}^{3}\right)+\sum_{t s} \Delta C_{t} \varkappa_{t s}+\sum_{s}\left(B-P_{b 1}-E_{b}\right) \Upsilon_{s}+\sum_{i j v t s} \pi_{i j v s}^{t}
\end{aligned}
$$


Subject to:

$$
\begin{aligned}
& \Pi_{i j t s}^{1}-\digamma_{i j t s}^{2} \geq \beta \varepsilon_{s}\left(\frac{S E_{i j 1}}{A_{i j 1 s}}+\frac{C S_{i j 1}}{A_{i j 1 s}}\right) \forall i, j, t, s \\
& 4_{i j t s}^{1}+\zeta_{i j t s}^{2}+e_{1} \varkappa_{t s}+\left(\gamma_{1}+\theta_{1}+D_{i j} V_{1}\right) x_{s} \\
& \geq \alpha \varepsilon_{s}\left(p_{1 s}^{t}-\gamma_{1}-\theta_{1}-D_{i j} V_{1}\right)+\beta \varepsilon_{s}\left(-S E_{i j 1} \frac{\phi}{A_{i j 1 s}}-C S_{i j 1} \frac{\xi}{A_{i j 1 s}}-\omega_{1}-D_{i j} \tau\right) \quad \forall i, j, t, s \\
& \Pi_{i j t s}^{2}+4_{i j t s}^{3}+\left(\gamma_{2}+\theta_{2}+D_{i j} V_{2}\right) \chi_{s} \\
& \geq \alpha \varepsilon_{s}\left(p_{2 s}^{t}-\gamma_{2}-\theta_{2}-D_{i j} V_{2}\right)+\beta \varepsilon_{s}\left(\frac{S E_{i j 2}}{A_{i j 2 s}}+\frac{C S_{i j 2}}{A_{i j 2 s}}-\omega_{2}-D_{i j} \tau\right) \forall i, j, t, s \\
& \Pi_{i j t s}^{2}+\zeta_{i j t s}^{4}+e_{3} \varkappa_{t s}+\left(\gamma_{3}+\theta_{3}+D_{i j} V_{3}\right) \chi_{s} \\
& \geq \alpha \varepsilon_{s}\left(p_{3 s}^{t}-\gamma_{3}-\theta_{3}-D_{i j} V_{3}\right)+\beta \varepsilon_{s}\left(\frac{S E_{i j 2}}{A_{i j 2 s}}+\frac{C S_{i j 2}}{A_{i j 2 s}}-\omega_{3}-D_{i j} \tau\right) \forall i, j, t, s \\
& \Pi_{i j t s}^{3}+\zeta_{i j t s}^{5}+e_{4} \mathcal{\varkappa}_{t s}+\left(\gamma_{4}+\theta_{4}+D_{i j} V_{4}\right) x_{s} \\
& \geq \alpha \varepsilon_{s}\left(p_{4 s}^{t}-\gamma_{4}-\theta_{4}-D_{i j} V_{4}\right)+\beta \varepsilon_{s}\left(-S E_{i j 2} \frac{\phi}{A_{i j 4 s}}-C S_{i j 2} \frac{\xi}{A_{i j 4 s}}-\omega_{4}-D_{i j} \tau\right) \forall i, j, t, s \\
& \Upsilon_{i j t s}^{1}-A_{i j 1 s} \pi_{t} 4_{i j t s}^{1}+\left(\delta_{1}+F_{1}\right) \chi_{s}+J_{i j 1 s}^{t} \geq \alpha \varepsilon_{s}\left(-\delta_{1}-F_{1}\right)+\beta \varepsilon_{s}\left(-\rho_{1}\right) \forall i, j, t, s \\
& Y_{i j t s}^{2}-A_{i j 2} L_{i j t s}^{3}+\left(\delta_{2}+F_{2}\right) X_{s}+J_{i j 2 s}^{t} \geq \alpha \varepsilon_{s}\left(-\delta_{2}-F_{2}\right)+\beta \varepsilon_{s}\left(-\rho_{2}\right) \forall i, j, t, s \\
& \mathrm{Y}_{i j t s}^{2}-A_{i j 3} \mathrm{~L}_{i j t s}^{4}+\left(\delta_{3}+F_{3}\right) X_{s}+J_{i j 3 s}^{t} \geq \alpha \varepsilon_{s}\left(-\delta_{3}-F_{3}\right)+\beta \varepsilon_{s}\left(-\rho_{3}\right) \forall i, j, t, s \\
& Y_{i j t s}^{3}-A_{i j 4} 4_{i j t s}^{5}+\left(\delta_{4}+F_{4}\right) X_{s}+J_{i j 4 s}^{t} \geq \alpha \varepsilon_{s}\left(-\delta_{4}-F_{4}\right)+\beta \varepsilon_{s}\left(-\rho_{4}\right) \forall i, j, t, s
\end{aligned}
$$

417 Constraints for variables

$418 \Pi_{i j t s}^{1}, \Pi_{i j t s}^{2}, \Upsilon_{i j t s}^{2} \in R$

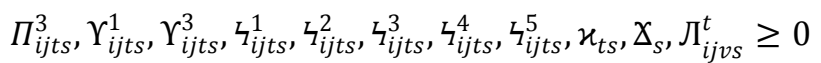

\subsubsection{Cutting Planes}

Algorithm steps of the Benders decomposition applied to the BFP problem are displayed in Fig.

3. First, we make settings in the decomposition algorithm by assigning 0 to the iteration counter, $n$, and infinity to $Z$ and tol, which gives the difference between the optimal objective function value of the dual SP and $Z^{*}$ (optimal value of $Z$ in the MP). In each iteration, first we check whether the iteration counter is less than the maximum number of iterations allowed (max iteration). If this condition is not met, then the best solution is displayed. Otherwise, the dual SP is solved. If the dual SP is unbounded, then a feasibility cut is added to the MP. If the dual SP is optimally solved, then an optimality cut is added to the MP. After this, MP is solved. If tol, which is updated by the difference between $Z^{*}$ and the dual SP 
optimal objective function value $\left(W^{*}\left(\underline{S}_{i j k}, \bar{G}_{i j k}\right)\right)$, is within the predefined epsilon distance, then a solution

431 is displayed. Otherwise, we continue iterations until either epsilon or the max iteration condition

432 terminates the algorithm. Note that by letting $S_{i j k}^{*}$ define the optimal solution of the MP, in each

433 iteration of the decomposition algorithm, we set $\underline{S}_{i j k}$ values in the dual problem to $S_{i j k}^{*}$ values.

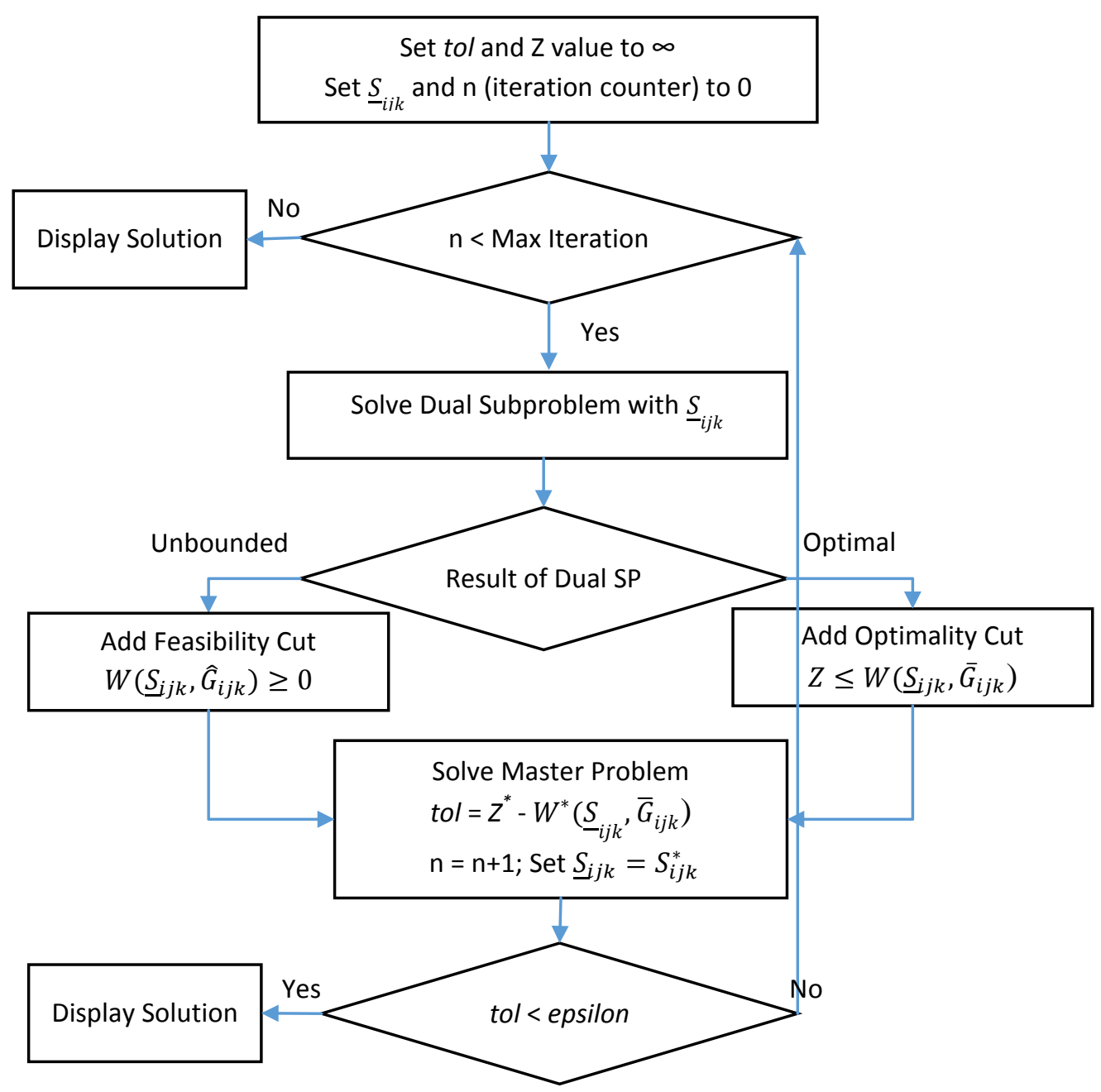

434

435

436

437

438

439

440

Fig.3. Flow chart of steps in proposed decomposition algorithm

In order to solve the master problem, feedback from the dual subproblem in the form of a cutting plane is returned to the MP after each iteration in the decomposition algorithm. Feasibility and optimality cuts are generated based on the solution of the dual SP and represented by inequalities b9 and b10, respectively. When the dual SP is unbounded, we obtain extreme dual rays $\left(\widehat{\Pi}_{i j t s}^{1}, \widehat{\Pi}_{i j t s}^{2}, \widehat{\Pi}_{i j t s}^{3}\right.$, $\widehat{\Upsilon}_{i j t s}^{1}, \widehat{\Upsilon}_{i j t s}^{2}, \widehat{\Upsilon}_{i j t s}^{3}, \widehat{\varkappa}_{t s}, \widehat{\mho}_{s}$, and $\widehat{\Pi}_{i j v s}^{t}$ ) and add the following feasibility cut to $\Omega^{\text {feas }}$ : 


$$
\begin{gathered}
\sum_{i j t s}\left(\left(A_{i j 1 s} \pi_{t} S_{i j 1}\right) \widehat{\Pi}_{i j t s}^{1}+\left(A_{i j 2 s} S_{i j 2}\right) \widehat{\Pi}_{i j t s}^{2}+\left(A_{i j 4 s} S_{i j 2}\right) \widehat{\Pi}_{i j t s}^{3}+S_{i j 2} \hat{\Upsilon}_{i j t s}^{1}+S_{i j 2} \hat{\Upsilon}_{i j t s}^{2}+S_{i j 2} \hat{\Upsilon}_{i j t s}^{3}\right)+\sum_{t s} \Delta C_{t} \hat{u}_{t s} \\
+\sum_{s}\left(B-P_{b 1}-E_{b}\right) \hat{\mho}_{s}+\sum_{i j v t s} \widehat{\Pi}_{i j v s}^{t} \geq 0
\end{gathered}
$$

441 Otherwise, if the dual is optimal but $Z^{*}$, representing the SP value in the MP, is not within the epsilon

442 distance of the dual SP optimal value, then we obtain an optimal extreme point solution $\left(\bar{\Pi}_{i j t s}^{1}, \bar{\Pi}_{i j t s}^{2}, \bar{\Pi}_{i j t s}^{3}\right.$,

$443 \bar{\Upsilon}_{i j t s}^{1}, \bar{Y}_{i j t s}^{2}, \bar{\Upsilon}_{i j t s}^{3}, \bar{\varkappa}_{t s}, \bar{X}_{s}$, and $\bar{\pi}_{i j v s}^{t}$ ) and add the following optimality cut to $\Omega^{\text {opt }}$ :

$$
\begin{gathered}
Z \leq \sum_{i j t s}\left(\left(A_{i j 1 s} \pi_{t} S_{i j 1}\right) \bar{\Pi}_{i j t s}^{1}+\left(A_{i j 2 s} S_{i j 2}\right) \bar{\Pi}_{i j t s}^{2}+\left(A_{i j 4 s} S_{i j 2}\right) \bar{\Pi}_{i j t s}^{3}+S_{i j 2} \bar{\Upsilon}_{i j t s}^{1}+S_{i j 2} \bar{\Upsilon}_{i j t s}^{2}+S_{i j 2} \bar{\Upsilon}_{i j t s}^{3}\right)+\sum_{t s} \Delta C_{t} \overline{\mathcal{X}}_{t s} \\
+\sum_{s}\left(B-P_{b 1}-E_{b}\right) \bar{X}_{s}+\sum_{i j v t s} \bar{\Pi}_{i j v s}^{t}
\end{gathered}
$$

444 The introduction of these cutting planes into the master problem continues until the algorithm is terminated with a solution. Note that Eqs. e1 and e2 represent the extended version of the constraints of the MP given as Eqs. b9 and b10, respectively.

\section{Case Study Data}

In this section, we present the data used for the application of the proposed model in a biorefinery project at Hugoton, Kansas. The area surrounding the biorefinery has three different cultivation land types: cropland, grassland (pasture land), and marginal land (land potentially in the Conservation Reserve Program [CRP]). The studied area is divided into 21 rows and 21 columns, where each zone is defined as the size of 260 ha (one square mile). Switchgrass is used for biofuel production, while corn is considered a source of both food and biofuel production. Switchgrass is cultivated on all land types, while corn production is only considered on cropland. The planning horizon is taken as ten years since the biorefinery enters into a contract with farmers, and switchgrass has about ten years of life. The following subsections present the remaining part of the input data. Readers can refer to the study of Cobuloglu and Büyüktahtakın (2015b) for a detailed explanation of the data.

\subsection{Yield Amount}

Here we explain the calculation for the stochastic yield amount of switchgrass and corn, which we expect to be affected in a similar way by weather conditions, e.g., higher precipitation would lead to a greater amount of corn and switchgrass yield. The corn yield and its price for 18 years are displayed in Fig. 4 (Feed Grains: Yearbook Tables, 2015). The yield amount of corn follows a normal distribution with parameters 8.49 for mean, 0.84 for standard deviation, 6.91 for the minimum value, and 10.68 for the maximum value. Based on the cumulative distribution of the given statistics of the distribution, the lowyield amount for corn grain is found to be less than or equal to 8.04 tonne/ha with $30 \%$ probability. 
Similarly, the high-yield amount of corn grain can be greater than or equal to 8.93 tonne/ha with $30 \%$

467 probability. Finally, the probability of observing a yield amount between the upper and lower bounds, 468 which we take as the mean value of 8.49 tonne/ha, is $40 \%$. Corn stover yield is taken as 1.1 times that of corn grain, based on the literature [30]. However, only half of that amount is harvestable to meet the 470 minimum requirements for soil erosion protection. Thus, harvestable corn stover is considered to be 4714.42 tonne/ha, 4.67 tonne/ha, and 4.91 tonne/ha with $30 \%, 40 \%$, and $30 \%$ probability, respectively. Test 472 statistics for the amount of switchgrass are 14.57 for mean, 3.55 for standard deviation, 9.5 for the 473 minimum value, and 20.5 for the maximum value (Fuentes \& Taliaferro, 2002). Based on this data, the 474 yield amount for switchgrass is defined as 12.71 tonne/ha, 14.57 tonne/ha, and 16.4 tonne/ha with $30 \%$, $47540 \%$, and 30\% probability, respectively. Therefore, by considering these three scenarios (low, average, 476 and high), we discretize the normal distributions for both corn and switchgrass. As described in the 477 problem definition section, we consider a total of 59,049 scenarios for a ten-year planning horizon.

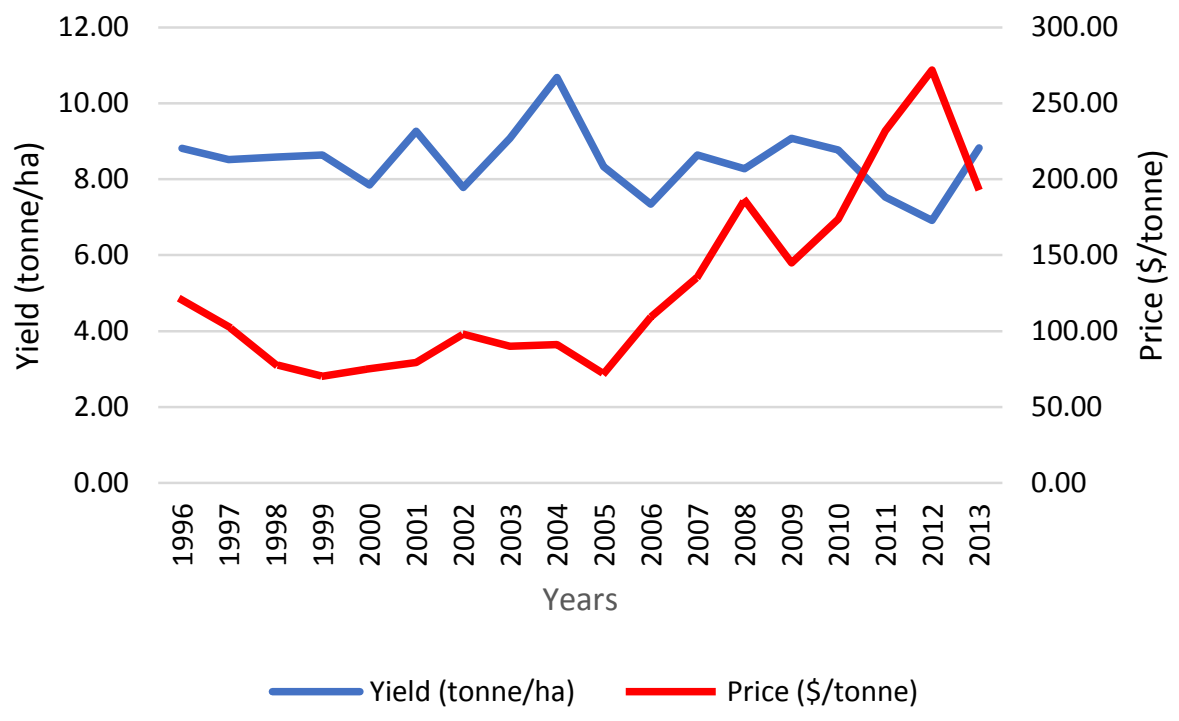

Fig. 4. Yield and price data of corn for eighteen years

The mean values for yield amount of switchgrass, corn grain, and corn stover are given in Table

481 1. Since switchgrass reaches its maximum potential yield at the third year, its yield amount changes until 482 the third year. It also has changing productivity rates on different land types. 
Table 1

Yield type, seeding location, and corresponding yield amounts

\begin{tabular}{lcccc}
\hline \multirow{2}{*}{ Yield type } & \multirow{2}{*}{ Land type } & \multicolumn{3}{c}{ Yield (tonne/ha) } \\
\cline { 3 - 5 } & & $\mathrm{t}=1$ & $\mathrm{t}=2$ & $\mathrm{t}=3-10$ \\
\hline Switchgrass & Cropland & 3.64 & 9.62 & 14.57 \\
Switchgrass & Grassland & 2.55 & 6.73 & 10.20 \\
Switchgrass & Marginal land & 1.82 & 4.81 & 7.29 \\
Corn grain & Cropland & 8.49 & 8.49 & 8.49 \\
Corn stover & Cropland & 9.34 & 9.34 & 9.34 \\
\hline
\end{tabular}

483

484

485

486

487

488

489

490

491

492

493

494

495

496

497

498

\subsection{Price}

The price level of corn grain in the food market is another uncertain parameter in the proposed stochastic model. Since the price of corn grain depends on yield amount, a linear regression model, provided in Fig. 5, is employed to define its level. Based on the data provided by the U.S. Department of Agriculture (McBride, 2014), the negative relation between corn price and yield is given as

$$
\text { Price }=-30.184(\text { Yield })+385.48
$$

Using this formula, the price levels of corn grain in the food market are defined as $142.80,129.22$, and $115.94 \$ /$ tonne for yield amounts of 8.04 tonne/ha, 8.49 tonne/ha, and 8.93 tonne/ha, respectively.

Due to contracts between farmers and the biorefinery, the constant biomass prices, namely 100 $\$ /$ tonne, $129.22 \$ /$ tonne, and $50 \$ /$ tonne are used for switchgrass, corn grain, and corn stover, respectively.

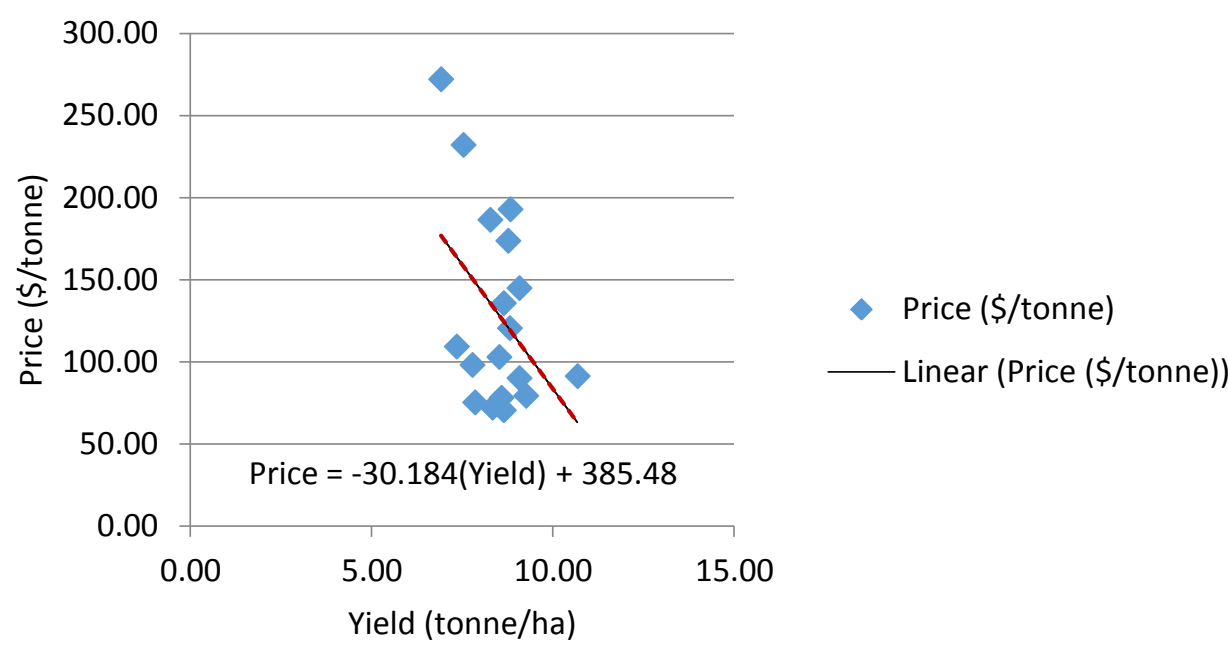

Fig. 5. Correlation between corn grain yield and its price level

\subsection{Production, Harvesting, and Transportation Cost}


The costs of different farm operations for switchgrass and corn cultivation are given in Table 2.

500 We use airflow planting for switchgrass establishment, while reduced tillage is considered for corn

501 seeding. An additional variable cost for the unloading and handling of biomass at the biorefinery is taken

502 as $\$ 1.88$ per tonne of biomass.

503

Table 2

Production, harvesting, and transportation cost for switchgrass and corn

\begin{tabular}{ccccccccccc}
\hline & \multirow{2}{*}{ Yield type } & \multirow{2}{*}{ Land type } & $\begin{array}{c}\text { Seeding } \\
(\$ / \mathrm{ha})\end{array}$ & $\begin{array}{c}\text { Rent } \\
(\$ / \mathrm{ha})\end{array}$ & $\begin{array}{c}\text { Fixed } \\
(\$ / \mathrm{ha})\end{array}$ & $\begin{array}{c}\text { Variable } \\
(\$ / \text { tonne) }\end{array}$ & $\begin{array}{c}\text { Fixed } \\
(\$ / \mathrm{ha})\end{array}$ & $\begin{array}{c}\text { Variable } \\
(\$ / \text { tonne })\end{array}$ & $\begin{array}{c}\text { Fixed } \\
(\$ / \mathrm{ha})\end{array}$ & $\begin{array}{c}\text { Variable } \\
(\$ / \text { tonne-km) }\end{array}$ \\
\hline Switchgrass & Cropland & 435.15 & 234.6 & 435.15 & 12 & 31.61 & 24.5 & 5.70 & 0.1367 \\
Switchgrass & Grassland & 445.77 & 23.7 & 445.77 & 12 & 31.61 & 24.5 & 5.70 & 0.1367 \\
Switchgrass & Marginal & 474.80 & 75.3 & 474.80 & 12 & 31.61 & 24.5 & 5.70 & 0.1367 \\
Corn & Cropland & 342.76 & 234.6 & 205.85 & 26 & 64.54 & 15.2 & - & 0.5 \\
Corn stover & Cropland & - & - & - & 22.33 & 14 & 9 & 5.70 & 0.1367 \\
\hline
\end{tabular}

504

\subsection{Soil Erosion, Carbon Sequestration, and other Environmental Impacts}

The economic value of savings from soil erosion and carbon sequestration is provided in Table 3.

507 The soil erosion value, carbon sequestered (C), its $\mathrm{CO}_{2}$ equivalence, and corresponding economic value

508 (savings) are given for each land type.

Table 3

Savings via soil erosion prevention and carbon sequestration

\begin{tabular}{|c|c|c|c|c|c|}
\hline \multirow[b]{2}{*}{ Yield type } & \multirow[b]{2}{*}{ Land type } & \multirow[b]{2}{*}{$\begin{array}{l}\text { Soil erosion } \\
\text { (\$/ha-year) }\end{array}$} & \multicolumn{3}{|c|}{ Carbon sequestration } \\
\hline & & & $\begin{array}{c}\mathrm{C} \\
\text { (Mg/ha-year) }\end{array}$ & $\begin{array}{l}\mathrm{CO}_{2} \text { equivalence } \\
\text { (tonne/ha-year) }\end{array}$ & $\begin{array}{c}\text { Savings } \\
\text { (\$/ha-year) }\end{array}$ \\
\hline Switchgrass & Cropland & 61.18 & 4.42 & 16.22 & 324.4 \\
\hline Switchgrass & Grassland & 9.89 & 3.2 & 1.17 & 23.5 \\
\hline Switchgrass & Marginal & 19.85 & 0.32 & 11.74 & 234.8 \\
\hline Corn & Cropland & -36.9 & 0.368 & 1.35 & 27 \\
\hline
\end{tabular}

509

Readers can refer to the previous work of Cobuloglu and Büyüktahtakın (2015b) for data

511 regarding the $\mathrm{CO}_{2}$ emissions, nitrogen pollution, and ethanol conversion rate for each biomass type.

512 5. Computational Results

513

In this section, we discuss the results of different mathematical solution approaches. The biofuel

514 and food production problem is solved using CPLEX version 12.2 on a desktop computer with $3.40 \mathrm{GHz}$

515 and 16 GB memory. The epsilon value (or duality gap tolerance), which gives the difference between the

516 upper and lower bounds in the decomposition algorithm, is set to 0.01 , similar to that of former

517 research applying Benders decomposition (Freund, 2004; Smith et al., 2009). The solution time for the 
stochastic model and Benders decomposition is set to one hour (3,600 CPU seconds), since a memory

519 problem is observed for longer times. The maximum number of iterations allowed for Benders decomposition is defined as 500. The computational time limitation of 3,600 CPU seconds is hit faster

521 than performing the algorithm for 500 iterations, as shown in Tables 4 and 5. Therefore, a maximum of

522500 iterations is reasonable for our particular application. Scenarios in the stochastic model are reduced

523 to one, where yield amounts are set to mean values in order to obtain a deterministic model. Solution

524 statistics for the deterministic model, stochastic model, and decomposition algorithm are presented in

525 Table 4. The impact of varying the objective function weights and budget levels over the objective value

526 (Obj Val), optimality gap reported by CPLEX (Gap), and solution time (CPU) are given for the

527 deterministic, stochastic, and decomposition models, respectively. We also present the number of

528 iterations required to solve the problem by the decomposition algorithm (Iteration) in Table 4.

Table 4

Comparison of solution approaches

\begin{tabular}{ccccccccccccc}
\hline \multirow{2}{*}{$\begin{array}{c}\text { Objective } \\
\text { weights } \\
(\alpha ; \beta)\end{array}$} & $\begin{array}{c}\text { Budget } \\
\text { (M\$) }\end{array}$ & $\begin{array}{c}\text { Objerministic } \\
\text { Val } \\
\text { (M\$) }\end{array}$ & $\begin{array}{c}\text { Gap } \\
(\%)\end{array}$ & $\begin{array}{c}\text { CPU } \\
(\mathrm{sec})\end{array}$ & $\begin{array}{c}\text { Obj } \\
\text { Val } \\
(\mathrm{M} \$)\end{array}$ & $\begin{array}{c}\text { Gap } \\
(\%)\end{array}$ & $\begin{array}{c}\text { CPU } \\
(\mathrm{sec})\end{array}$ & $\begin{array}{c}\text { Obj } \\
\text { Val } \\
(\mathrm{M} \$)\end{array}$ & $\begin{array}{c}\text { Gap } \\
(\%)\end{array}$ & $\begin{array}{c}\text { CPU } \\
(\mathrm{sec})\end{array}$ & Iteration \\
\hline$(1 ; 0)$ & 500 & 206.9 & 0.05 & 354.2 & 221.3 & 2.19 & 3600 & 223.1 & 0.83 & 3600 & 131 \\
$(1 ; 0)$ & 750 & 257.8 & 0.05 & 651.1 & 276.1 & 1.94 & 3600 & 278.3 & 0.66 & 3600 & 175 \\
$(1 ; 0)$ & 1000 & 294.1 & 0.05 & 122.7 & 318.5 & 1.69 & 3600 & 320.9 & 0.39 & 3600 & 143 \\
$(0.5 ; 0.5)$ & 500 & 135.3 & 0.05 & 105.1 & 145.8 & 2.29 & 3600 & 146.4 & 0.89 & 3600 & 166 \\
$(0.5 ; 0.5)$ & 750 & 150.2 & 0.05 & 547.0 & 161.9 & 2.08 & 3600 & 162.2 & 0.77 & 3600 & 121 \\
$(0.5 ; 0.5)$ & 1000 & 161.4 & 0.05 & 18.7 & 173.4 & 1.79 & 3600 & 174.8 & 0.48 & 3600 & 117 \\
$(0 ; 1)$ & 500 & 112.2 & 0.05 & 26.7 & 119.9 & 1.96 & 3600 & 120.7 & 0.67 & 3600 & 101 \\
$(0 ; 1)$ & 750 & 130.4 & 0.05 & 4.1 & 139.1 & 1.73 & 3600 & 140.4 & 0.43 & 3600 & 112 \\
$(0 ; 1)$ & 1000 & 134.6 & 0.05 & 5.8 & 143.0 & 1.59 & 3600 & 144.1 & 0.37 & 3600 & 118 \\
\hline
\end{tabular}

529

530

531

532

533

534

535

536

537

538

539

It can be seen that the objective value of the deterministic model is less than the objective values of other models. This is because the stochastic model provides better strategies under uncertainty. On the other hand, the objective value of the decomposition model is greater than the stochastic model, and the optimality gap in the decomposition is as small as $32 \%$ of the gap in the stochastic model in average. The difference in solution quality between the deterministic and stochastic models indicates the necessity of decision making under uncertainty. These results also indicate that the development of a decomposition model for the given problem is of great importance in order to observe maximum benefits. However, the solution time for the deterministic model is considerably less than the solution time for the stochastic model and its decomposition. Note that a gap of $0.05 \%$ is set for the deterministic model in order to not encounter memory problems. On the other hand, the optimality gap 
of the stochastic model is between $1.6 \%$ and $2.3 \%$, which reduces to $0.37 \%$ and $0.89 \%$ in the decomposition for the same cases with higher-quality solutions. Another observation for the given experiments involves problem complexity. As the budget becomes larger, the solution quality in the stochastic and decomposition approaches increases.

In another experiment, we compare the stochastic MIP model and the decomposition algorithm with respect to their solution speeds. In this experiment, we set a time limit of 7,200 CPU seconds and a gap of $0.10 \%$. In order to observe the differences easily, the size of the region is reduced from a 21 -by21 matrix to a 10-by-10 matrix. The solution statistics of the stochastic model and the decomposition for different objective weights and budget levels are presented in Table 5. We observe that the decomposition algorithm reaches a solution within an hour for all instances. However, the solution time for the stochastic model is longer than that for the decomposition algorithm. When the budget is limited, the complexity of the problem increases. In particular, the problem reaches the highest complexity when equal weight is given to each of the objective functions. Under a limited budget in profit prioritization $(1 ; 0)$ and equal weight $(0.5 ; 0.5)$ cases, the solution time of the decomposition approach is almost two times faster than the solution time of the stochastic MIP. The overall average solution speed for the nine presented cases indicates that the decomposition method uses only $63.4 \%$ of the time required for a solution in the stochastic model.

Table 5

Comparison of stochastic programming and decomposition algorithm

\begin{tabular}{ccccccccc}
\hline \multirow{2}{*}{$\begin{array}{c}\text { Objective } \\
\text { weights } \\
(\alpha ; \beta)\end{array}$} & $\begin{array}{c}\text { Budget } \\
(\mathrm{M} \$)\end{array}$ & $\begin{array}{c}\text { Obj } \\
\text { Val } \\
(\mathrm{M} \$)\end{array}$ & $\begin{array}{c}\text { Gap } \\
(\%)\end{array}$ & $\begin{array}{c}\text { CPU } \\
(\mathrm{sec})\end{array}$ & $\begin{array}{c}\text { Obj } \\
\text { Val } \\
(\mathrm{M} \$)\end{array}$ & $\begin{array}{c}\text { Gap } \\
(\%)\end{array}$ & $\begin{array}{c}\text { CPU } \\
(\mathrm{sec})\end{array}$ & Iteration \\
\hline$(1 ; 0)$ & 125 & 56.7 & 0.10 & 6128 & 56.7 & 0.10 & 3117 & 149 \\
$(1 ; 0)$ & 187.5 & 70.6 & 0.10 & 4957 & 70.6 & 0.10 & 2810 & 182 \\
$(1 ; 0)$ & 250 & 81.1 & 0.10 & 3421 & 81.1 & 0.10 & 2419 & 154 \\
$(0.5 ; 0.5)$ & 125 & 37.5 & 0.10 & 6407 & 37.5 & 0.10 & 3136 & 177 \\
$(0.5 ; 0.5)$ & 187.5 & 41.3 & 0.10 & 5168 & 41.3 & 0.10 & 2984 & 132 \\
$(0.5 ; 0.5)$ & 250 & 44.5 & 0.10 & 3560 & 44.5 & 0.10 & 2576 & 133 \\
$(0 ; 1)$ & 125 & 31.2 & 0.10 & 4189 & 31.2 & 0.10 & 2878 & 129 \\
$(0 ; 1)$ & 187.5 & 36.3 & 0.10 & 3230 & 36.3 & 0.10 & 2722 & 146 \\
$(0 ; 1)$ & 250 & 37.8 & 0.10 & 3020 & 37.8 & 0.10 & 2751 & 124 \\
\hline \multicolumn{2}{l}{ Overall average } & - & - & 4453 & - & - & 2821 & - \\
\hline
\end{tabular}

\subsection{Sensitivity Analysis}

In this section, we discuss the impact of key parameters on the solution. First, we analyze the impact of changing the food security factor on solutions of the deterministic, stochastic, and 
decomposition models. For this experiment, the budget is set to $750 \mathrm{M} \$$, and priority is given to profit with the objective function weights (1;0). Figs. 6 and 7 display the impact of changing the food security factor on the economic values and environmental impacts, respectively. Fig. 6 indicates that the deterministic model estimates the economic values to be lower in all cases when compared with results of the stochastic and decomposition models. We also observe that increasing the land availability for switchgrass (decreasing food security) leads to higher objective values in all models. This is because as we change the food security from $100 \%$ to $50 \%$, more cropland becomes available for switchgrass cultivation. Switchgrass is more profitable on cropland than corn. Please note that, as we display the objective function value in Fig. 6, the difference between the stochastic and deterministic models provides the benefit of solving the stochastic model over its deterministic counterpart.

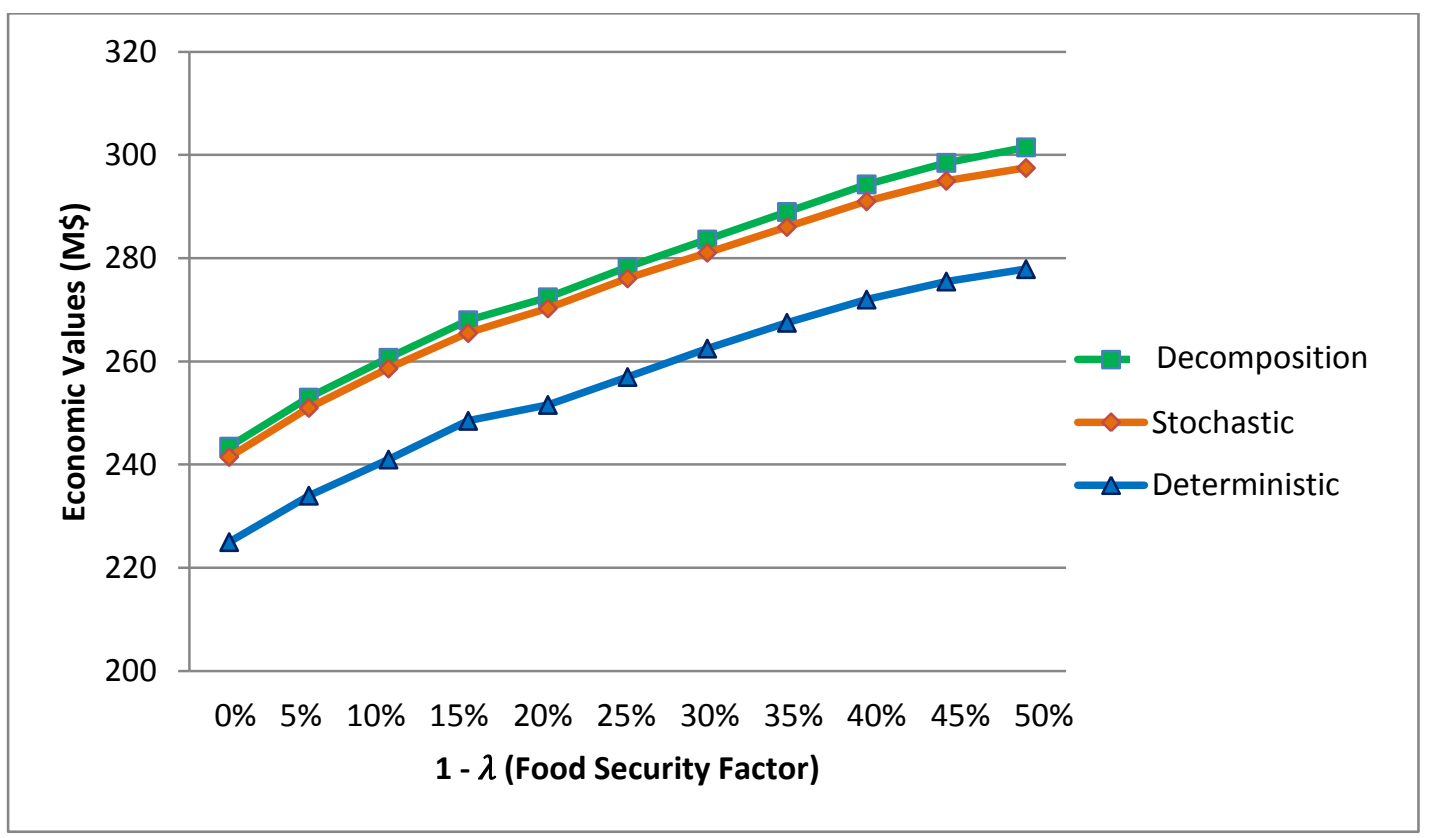

Fig. 6. Economic values provided by different mathematical approaches when profit is maximized Fig. 7 displays interesting insights relative to environmental impacts of changing the food security factor. Note that this figure provides environmental impacts when priority is given to profit in the objective function. As the land availability for switchgrass decreases (food security increases), switchgrass production on cropland is limited, and the majority of cropland becomes available for only corn production. Since the models focus on profit, when the food security factor is set to $100 \%$, the overall negative environmental impacts of corn become higher than the benefits provided by switchgrass production. We also observe that the total environmental impacts of corn and switchgrass are lower when estimated by the deterministic model. Thus, net environmental impacts become 


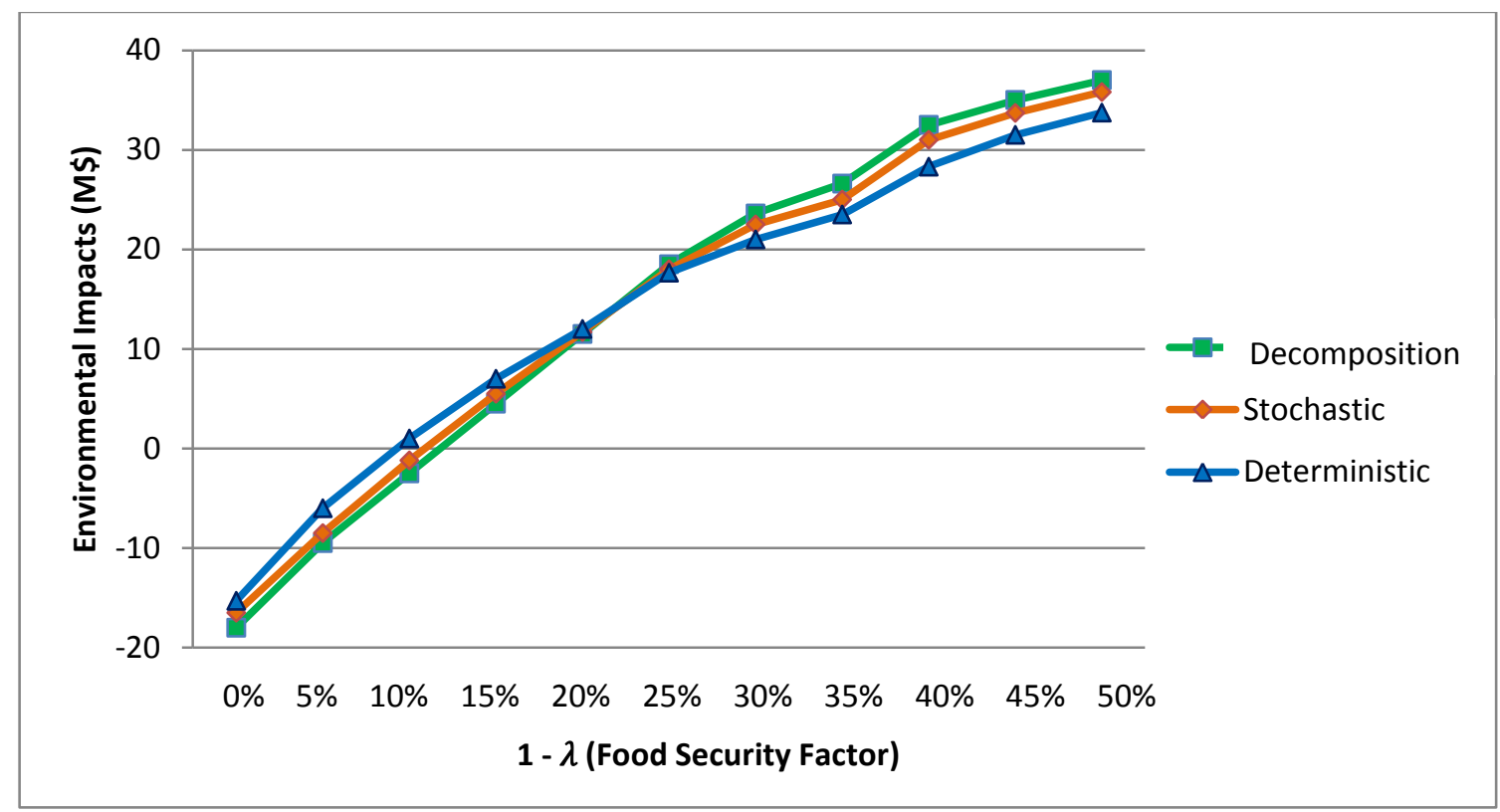

Fig. 7. Environmental impacts provided by different mathematical approaches when profit is maximized We also compare results of the stochastic and deterministic models to analyze the benefit of solving the stochastic problem under various budget cases. Fig. 8 displays the benefit of a stochastic model solution over its deterministic counterpart when priority is given only to profit, while Fig. 9 presents results when priority is given only to the environment. We observe that as the budget increases, the benefit from the stochastic model becomes significantly important. In other words, since a higher budget leads to higher land utilization, the difference between results of the stochastic and deterministic models increases in the profit maximization. When there is ample budget for land utilization, the benefit from the stochastic model increases reaching a saturation point and then stops.

Fig. 9 displays the benefit of stochastic solution when priority is given only to environmental benefits in the objective function. When we compare results of profit maximization and environmental benefit maximization, we observe that the benefit from the stochastic model when environmental objectives are maximized is lower than the related benefit in the profit maximization case, as expected. That is because the magnitude of economic outcomes is larger than the magnitude of environmental benefits. The difference between the deterministic and stochastic models is smaller than $\$ 2 \mathrm{M}$ when we utilize the $\$ 100 \mathrm{M}$ budget. On the other hand, the increment in the benefit from the stochastic model becomes stable after $\$ 800 \mathrm{M}$. That is because $\$ 800 \mathrm{M}$ is sufficient to utilize all land types in the environmental benefit maximization case when compared to profit maximization. 


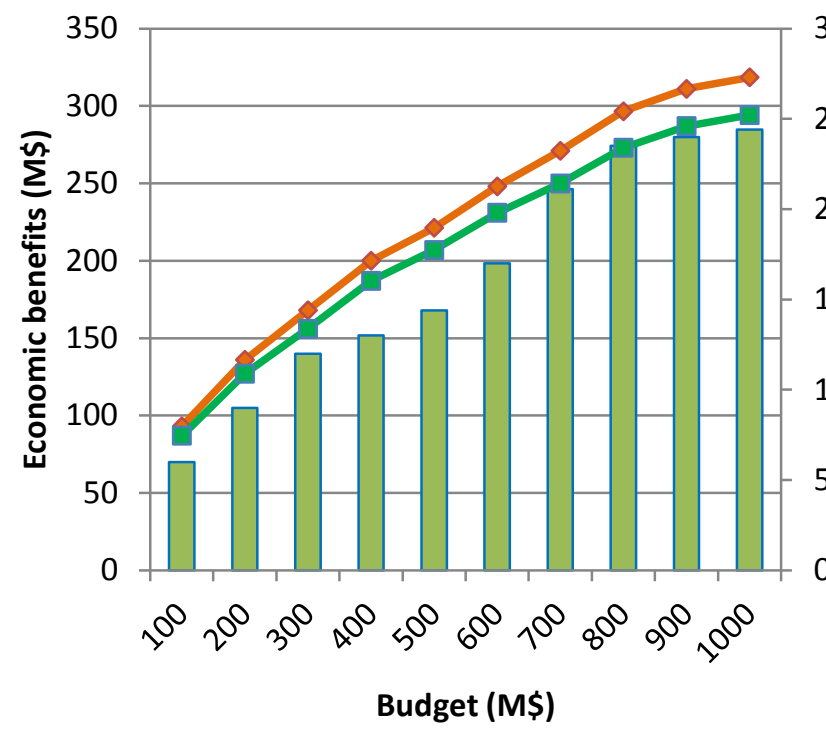

30

25

20

15

5

๓ั
Benefit of stochastic model

$\sim$ Stochastic economic benefits

-Deterministic economic benefits

Fig. 8. Comparison of stochastic and deterministic models under profit maximization

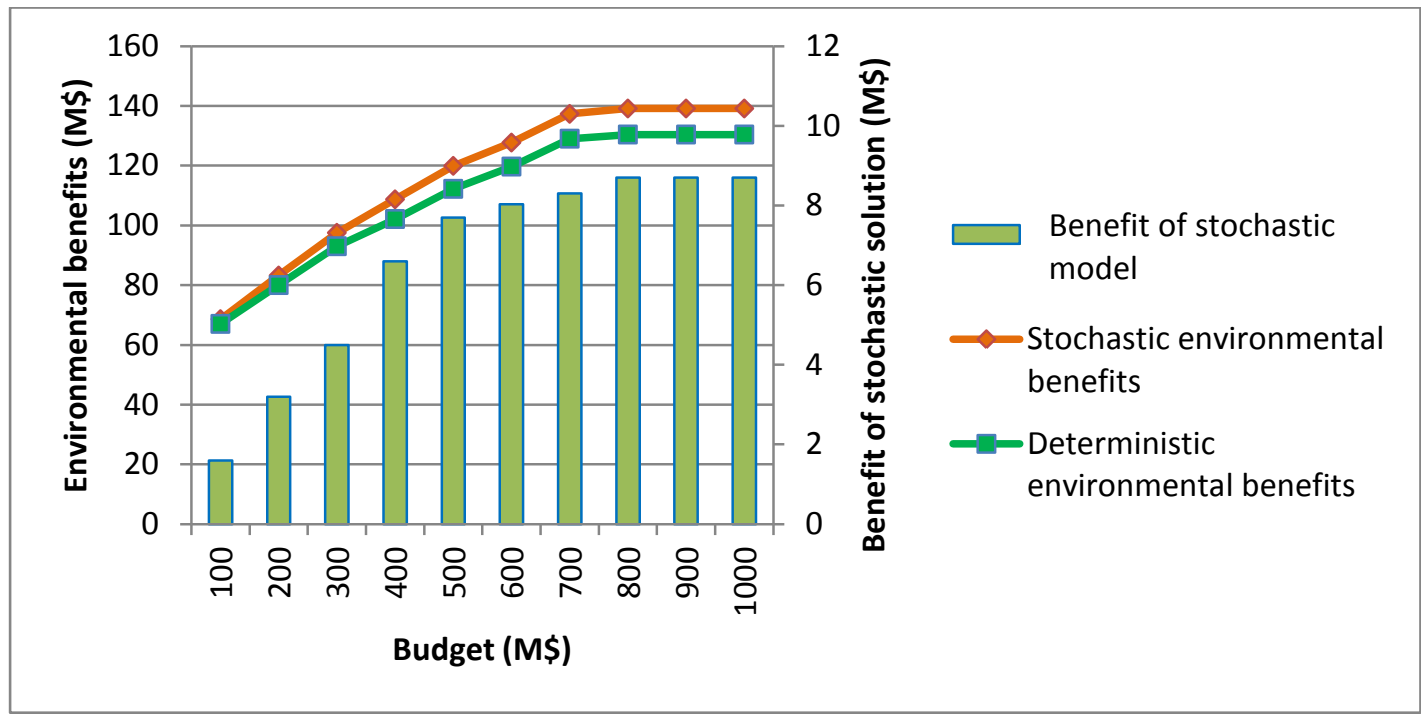

605 Fig. 9. Comparison of stochastic and deterministic models under environmental benefits maximization

606

607

608

609

610

611

612

613

\section{Conclusion and Discussion}

In this paper, we develop a two-stage stochastic MIP model for food and biofuel production at the farm level. In order to model uncertainty in the yield amount of crops and price level of corn in the market, we consider a scenario-based stochastic optimization approach. For that purpose, yield and price data provided by the USDA are analyzed. We define low-, medium-, and high-yield amounts for each crop type with corresponding probabilities. The associated price level for each yield is also integrated into the scenarios. We first solve the problem as a stochastic MIP model. In order to overcome complexities arising from the size of the model, we decompose the problem into a master 
problem (land allocation level) and a subproblem (operational level) and employ Benders cuts to find a 615 solution.

Application of the model is demonstrated for a biorefinery project in Kansas. Deterministic,

617 stochastic, and decomposition models are utilized for various cases. The objective function of three

618 models shows that both stochastic and decomposition models outperform the deterministic model. The

619 proposed decomposition model is also more efficient than the stochastic model in terms of solution quality. The sensitivity analysis provides important insights for food and biofuel production. Based on the food security factor, the limitation of energy crop production on cropland sacrifices the environmental benefits. As the corn production increases on cropland, associated negative impacts also increase. We also observe that the deterministic model underestimates both economic and environmental benefits. Another analysis of comparing the solutions of stochastic and deterministic models shows that obtaining stochastic information is significantly important when we seek to maximize profit. That is because the magnitude of economic impacts is higher than the value of environmental impacts in the objective function.

The proposed stochastic model can be utilized for various food and biofuel production problems in different regions. In the future, a more complex data analysis could be performed in order to refine the model inputs. In particular, neural networks could be used as a data analytics tool in order to

632 and rainfall, and soil moisture data (Uhrig et al, 1992; Reddy and Pachepsky, 2000). Furthermore, more uncertainties on the demand side as well as budget and invasiveness of some crop types (Kibis and Büyüktahtakın, 2017) could be involved in the decision-making process. However, that would decrease the solvability due to the size of the problem. In order to overcome the potential complexity, a scenario reduction technique may be applied. In addition, more specialized cutting planes in the master problem and dynamic programming-based cuts proposed by Hartman et al. (2010) could be investigated for increasing the solution speed of the model. In case the probability distribution is difficult to obtain, then robust optimization models could be developed. The proposed model could also be adapted to other

640 biomass and food crops that have similar characteristics to corn and switchgrass in order to determine 641 the most effective land allocation and production policies under yield and price uncertainty. 


\section{References}

646

647

648

649

650

651

652

653

654

655

656

657

658

659

660

661

662

663

664

665

666

667

668

669

670

671

672

673

674

675

676

677

678

679

680

Affuso, E., \& Hite, D. (2013). A model for sustainable land use in biofuel production: An application to the state of Alabama. Energy Economics, 37, 29-39.

Benders, J. F. (1962). Partitionning procedures for solving mixed-variable programming problems. Numerische Mathematik, 4, 238-252.

Birge, J. R., \& Louveaux, F. (1997). Introduction to stochastic programming (1st ed.). New York: Springer.

Chang, W. R., Hwang, J. J., \& Wu, W. (2017). Environmental impact and sustainability study on biofuels for transportation applications. Renewable and Sustainable Energy Reviews, 67, 277-288.

Chen, C.-W., \& Fan, Y. (2012). Bioethanol supply chain system planning under supply and demand uncertainties. Transportation Research Part E: Logistics and Transportation Review, 48(1), 150164.

Cobuloglu, H. I., \& Büyüktahtakın, İ. E. (2014). A mixed-integer optimization model for the economic and environmental analysis of biomass production. Biomass and Bioenergy, 67(C), 8-23. doi:10.1016/j.biombioe.2014.03.025

Cobuloglu, H. I., \& Büyüktahtakın, İ. E. (2015a). A stochastic multi-criteria decision analysis for sustainable biomass crop selection. Expert Systems with Applications, 42(15), 6065-6074.

Cobuloglu, H. I., \& Büyüktahtakın, İ. E. (2015b). Food vs. biofuel: An optimization approach to the spatiotemporal analysis of land-use competition and environmental impacts. Applied Energy, 140, 418-434.

Feed Grains: Yearbook Tables. (2015, March 13). Retrieved on February 16, 2015 from USDA's Economic Research Service: http://www.ers.usda.gov/data-products/feed-grains-database/feed-grainsyearbook-tables.aspx

Freund, R. M. (2004). Benders' decomposition methods for structured optimization, including stochastic optimization. Massachusetts Institute of Technology.

Fuentes, R. G., \& Taliaferro, C. M. (2002). Biomass yield stability of switchgrass cultivars. In J. Janick and A. Whipkey (eds.). Trends in new crops and new uses (pp. 276-82). Alexandria, VA: ASHS Press.

García, C. A., Manzini, F., \& Islas, J. M. (2016). Sustainability assessment of ethanol production from two crops in Mexico. Renewable and Sustainable Energy Reviews. In press.

Gebreslassie, B. H., Yao, Y., \& You, F. (2012). Design under uncertainty of hydrocarbon biorefinery supply chains: Multiobjective stochastic programming models, decomposition algorithm, and a comparison between CVaR and downside risk. AIChE Journal, 58(7), 2155-79.

Giarola, S., Shah, N., \& Bezzo, F. (2012). A comprehensive approach to the design of ethanol supply chains including carbon trading effects. Bioresource Technology, 107, 175-185.

Gonela, V., Zhang, J., \& Osmani, A. (2015). Stochastic optimization of sustainable industrial symbiosis based hybrid generation bioethanol supply chains. Computers \& Industrial Engineering, 87, 4065. 
681

682

683

684

685

686

687

688

689

690

691

692

693

694

695

696

697

698

699

700

701

702

703

704

705

706

707

708

709

710

711

712

713

714

715

716

717

Hartman, J. C., Büyüktahtakin, İ. E., \& Smith, J. C. (2010). Dynamic-programming-based inequalities for the capacitated lot-sizing problem. IIE Transactions, 42(12), 915-930.

Kantas, A. B., Cobuloglu, H. I., \& Büyüktahtakın, I. E. (2015). Multi-source capacitated lot-sizing for economically viable and clean biofuel production. Journal of Cleaner Production, 94, 116-129. doi:10.1016/j.jclepro.2015.02.001

E. Kibis and I. E. Büyüktahtakın (2017). Optimizing Invasive Species Management: A Mixed-Integer Linear Programming Approach. European Journal of Operational Research, 259, 308-321. doi.org/10.1016/j.ejor.2016.09.049

Liebig, M. A., Schmer, M. R., Vogel, K. P., \& Mitchell, R. B. (2008). Soil Carbon storage by switchgrass grown for bioenergy. Bionenergy Resource, 1, 215-222.

Lin, T., Rodríguez, L. F., Shastri, Y. N., Hansen, A. C., \& Ting, K. C. (2014). Integrated strategic and tactical biomass-biofuel supply chain optimization. Bioresource Technology, 156, 256-266.

Liu, Z., Qiu, T., \& Chen, B. (2014). A study of the LCA based biofuel supply chain multi-objective optimization model with multi-conversion paths in China. Applied Energy, 126, 221-234.

McBride, W. (2014, December 15). Commodity Costs and Returns. Retrieved on February 16, 2015 from USDA's Economic Research Service: http://ers.usda.gov/data-products/commodity-costs-andreturns.aspx

Marufuzzaman, M., Eksioglu, S. D., \& Huang, Y. E. (2014). Two-stage stochastic programming supply chain model for biodiesel production via wastewater treatment. Computers \& Operations Research, 49, 1-17.

Mogale, D. G., Kumar, S. K., \& Tiwari, M. K. (2016). Two stage Indian food grain supply chain network transportation-allocation model. IFAC-PapersOnLine, 49(12), 1767-1772.

Mogale, D. G., Kumar, S. K., Márquez, F. P. G., \& Tiwari, M. K. (2017). Bulk wheat transportation and storage problem of public distribution system. Computers \& Industrial Engineering, 104, 80-97.

Ravindranath, N. H., Lakshmi, C. S., Manuvie, R., \& Balachandra, P. (2011). Biofuel production and implications for land use, food production and environment in India. Energy Policy, 39(10), 5737-5745.

Reddy, V. R., \& Pachepsky, Y. A. (2000). Predicting crop yields under climate change conditions from monthly GCM weather projections. Environmental Modelling \& Software, 15(1), 79-86.

Schnepf, R., \& Yacobucci, B. D. (2010, March 14). Renewable Fuel Standard (RFS): Overview and issues. Washington: Congressional Research Service. Retrieved December 4, 2013, from http://www.fas.org/sgp/crs/misc/R40155.pdf

Shapiro, A., Dentcheva, D., \& Ruszczyński, A. (2009). Lectures on stochastic programming: Modeling and theory (1st ed.). Philadelphia: Society for Industrial and Applied Mathematics.

Sharma, B., Ingalls, R. G., Jones, C. L., Huhnke, R. L., \& Khanchi, A. (2013). Scenario optimization modeling approach for design and management of biomass-to-biorefinery supply chain system. Bioresource Technology, 150, 163-171. 
Sherali, H. D., \& Fraticelli, B. M. (2002). A modification of Benders' decomposition algorithm for discrete subproblems: An approach for stochastic programs with integer recourse. Journal of Global Optimization, 22(1-4), 319-342.

Smith, J. C., Lim, C., \& Alptekinoğlu, A. (2009). New product introduction against a predator: A bilevel mixed-integer programming approach. Naval Research Logistics (NRL), 56(8), 714-729.

Tasca, A. L., Nessi, S., \& Rigamonti, L. (2017). Environmental sustainability of agri-food supply chains: An LCA comparison between two alternative forms of production and distribution of endive in northern Italy. Journal of Cleaner Production, 140, 725-741.

Tong, K., Gleeson, M. J., Rong, G., \& You, F. (2014). Optimal design of advanced drop-in hydrocarbon biofuel supply chain integrating with existing petroleum refineries under uncertainty. Biomass and Bioenergy, 60, 108-120.

Uhrig, J. W., Engel, B. A., \& Baker, W. L. (1992, January). An application of neural networks: Predicting corn yields. In Computers in agricultural extension programs: Proceedings of the NCR-134 Conference on Applied Commodity Price Analysis, Forecasting, and Market Risk Management (pp. 28-31). Chicago, IL. [http://www.farmdoc.uiuc.edu/nccc134].

Venema, H. D., \& Calamai, P. H. (2003). Bioenergy systems planning using location-allocation and landscapes ecology design principles. Annals of Operations Research, 123, 241-264.

Wiedenmann, S., \& Geldermann, J. (2015). Supply planning for processors of agricultural raw materials. European Journal of Operational Research, 242, 606-619.

Wu, J., \& Sen, S. (2000). A stochastic programming model for currency option hedging. Annals of Operations Research, 100(1-4), 227-249.

Zhang, L., Hu, G., Wang, L., \& Chen, Y. (2015). A bottom-up biofuel market equilibrium model for policy analysis. Annals of Operations Research. doi:10.1007/s10479-013-1497-y. 